\title{
Requirements for proximal tubule epithelial cell detachment in response to ischemia: Role of oxidative stress
}

\author{
David Sáenz-Morales $^{a, b}$, María M. Escribese ${ }^{a}$, Konstantinos Stamatakisc, \\ María García-Martos ${ }^{a}$, Laura Alegre ${ }^{a}$, Elisa Conde ${ }^{a}$, Dolores Pérez-Sala ${ }^{c}$, \\ Francisco Mampaso $^{a, b}$, M. Laura García-Bermejo ${ }^{a, *}$ \\ a Department of Pathology, Hospital Univ. Ramón y Cajal, Crta. de Colmenar, Km 9,1, 28034, Madrid, Spain \\ buniversidad Alcalá de Henares, Madrid, Spain \\ ${ }^{\mathrm{C} D e p a r t m e n t}$ of Protein Structure and Function, Centro de Investigaciones Biológicas, CSIC, Madrid, Spain
}

\section{A R T I C L E I N F O R M A T I O N}

Article Chronology:

Received 20 January 2006

Revised version received

18 May 2006

Accepted 28 May 2006

Available online 12 September 2006

Keywords:

Cell adhesion

Hypoxia/reoxygenation

Actin cytoskeleton

Focal adhesion complexes

Adherens junctions

ROS

RhoGTPases

\begin{abstract}
A B S T R A C T
Sublethal renal ischemia induces tubular epithelium damage and kidney dysfunction. Using NRK-52E rat proximal tubular epithelial cells, we have established an in vitro model, which includes oxygen and nutrients deprivation, to study the proximal epithelial cell response to ischemia. By means of this system, we demonstrate that confluent NRK-52E cells lose monolayer integrity and detach from collagen IV due to: (i) actin cytoskeleton reorganization; (ii) Rac1 and RhoA activity alterations; (iii) Adherens junctions (AJ) and Tight junctions (TJ) disruption, involving redistribution but not degradation of E-cadherin, $\beta$-catenin and ZO-1; (iv) focal adhesion complexes (FAC) disassembly, entangled by mislocalization of paxillin and FAK dephosphorylation. Reactive oxygen species (ROS) are generated during the deprivation phase and rapidly balanced at recovery involving MnSOD induction, among others. The use of antioxidants (NAC) prevented FAC disassembly by blocking paxillin redistribution and FAK dephosphorylation, without abrogating AJ or TJ disruption. In spite of this, NAC did not show any protective effect on cell detachment. $\mathrm{H}_{2} \mathrm{O}_{2}$, as a pro-oxidant treatment, supported the contribution of ROS in tubular epithelial cell-matrix but not cell-cell adhesion alterations. In conclusion, ROS-mediated FAC disassembly was not sufficient for the proximal epithelial cell shedding in response to sublethal ischemia, which also requires intercellular adhesion disruption.
\end{abstract}

(c) 2006 Elsevier Inc. All rights reserved.

\footnotetext{
* Corresponding author. Fax: +34 913369016.

E-mail address: mgarciab.hrc@salud.madrid.org (M.L. García-Bermejo).
} 


\author{
Abbreviations: \\ $\mathrm{ABP}$, actin binding protein \\ $\mathrm{AJ}$, adherens junctions \\ ECM, extracellular matrix \\ FAC, focal adhesion complexes \\ $\mathrm{H} / \mathrm{R}$, hypoxia/reoxygenation \\ $\mathrm{I} / \mathrm{R}$, ischemia/reperfusion \\ MnSOD, manganese \\ superoxide dismutase \\ NAC, $N$-acetylcysteine \\ NRK-52E, normal rat kidney \\ epithelial cells \\ ROS, reactive oxygen species \\ TJ, tight junctions
}

\section{Introduction}

$\mathrm{I} / \mathrm{R}$ is at the basis of severe clinical processes including stroke, cardiac infarct, acute renal failure and organ transplantation. Renal ischemia induces a broad range of cell responses including loss of adhesion and cell death, depending on the cell type and the duration of the ischemic period. Sublethal renal I/R provokes primarily proximal tubular epithelial cell shedding [1]. Using animal models of $\mathrm{I} / \mathrm{R}$, loss of epithelial polarity, actin cytoskeleton dynamics alterations and disruption of intercellular junctions have been reported in the proximal tubule [2]. The contribution of ischemia to tubular injury has also been studied using chemical anoxia models and ATP depletion of cultured cells, leading to cell death in many cell types including tubular epithelial cells [3]. Nevertheless, sublethal ischemia does not lead primarily to tubular epithelial cell death. Therefore, for an appropriate study of the epithelial cell response to $\mathrm{I} / \mathrm{R}$, it is important to use in vitro systems which closely reproduce the in vivo experimental conditions and effects.

The morphology and the correct function of proximal tubular epithelial cells are determined by the structured cytoskeleton, the organized intercellular unions as well as the firm focal contacts with the ECM. Regarding the actin cytoskeleton, several authors have reported actin cytoskeleton reorganization in response to ATP depletion and to anoxia in cultured kidney epithelial cells [4]. RhoGTPases are key molecular regulators of actin cytoskeleton dynamics (assembly and contraction), switching between an active GTP-bound state and an inactive GDP-bound form [5]. Inactivation of RhoA has been implicated in the disruption of stress fibers caused by ATP depletion in proximal tubular epithelial cells $[6,7]$. Recently, Caron et al. [8] demonstrated that renal I/R modifies the expression and localization of Rac1, RhoA and Cdc42 in the proximal tubular fractions, correlating with alterations in $\beta$ actin and $\alpha$-tubulin expression and distribution. However, the role of RhoGTPases and the contribution of actin cytoskeleton dynamics to the proximal epithelial cell detachment induced by I/R still remains poorly defined.

Tubular epithelial cells are attached to the basal membrane where collagen IV is the major component. This anchorage is mediated by FAC, formed by actin microfilament bundles and several multi-protein complexes that include paxillin, focal adhesion kinase (FAK) and integrins, among others [9]. Little is known about alterations in the FAC in proximal tubular epithelial cells during renal ischemia. In this context, we have recently demonstrated that in vivo I/R induced dephosphorylation of FAK through $\beta 1$-integrin deactivation, thus contributing to the proximal epithelium impairment [10]. Weinberg et al. [11] reported alterations in phosphorylation and distribution of paxillin, FAK and $\alpha 6 \beta 1$ integrin in kidney proximal tubules submitted to anaerobic mitochondrial metabolism.

Epithelial cell-cell adhesion is established through different structures: tight junctions (TJ), adherens junctions (AJ) and desmosomes. AJ are integrated by cadherins, actin filaments, cytoskeleton associated proteins such as catenins and other signaling proteins [12]. I/R in proximal tubules as well as ATP depletion in MDCK cells caused E-cadherin/ $\beta$-catenin complex disruption by selective degradation of E-cadherin [13]. TJ assure a selective permeability barrier and maintain the polarized phenotype in epithelial cells [12]. They are composed by transmembrane proteins and cytoplasmic proteins such as ZO-1 connected to the actin cytoskeleton. $\mathrm{AJ}$ and $\mathrm{TJ}$ are structurally and functionally linked: TJ involves E-cadherin mediated cell-cell interactions [14]. ATP depletion in vitro models have shown transient disruption and reassembly of TJ $[15,16]$.

The ATP and oxygen alterations subsequent to I/R can lead to oxidative stress generation. Indeed, several authors have documented the production of reactive oxygen species (ROS) and reactive nitrogen species (RNS), in animal models of $I / R$ and in chemical hypoxia/ATP depletion in vitro models. Additionally, the administration of antioxidants showed beneficial effects on both in vivo and in vitro systems [17]. Although the implication of oxidative stress in $I / R$ renal damage is widely admitted, its contribution to proximal tubular epithelial cell detachment remains quite unexplored. Regarding this, van Wetering et al. [18] have reported the involvement of ROS in the regulation of AJ function through Rac1, in human endothelial cells. In addition, oxidative conditions through tyrosine phosphorylation of $\mathrm{AJ}$ and $\mathrm{TJ}$ proteins might induce redistribution of those proteins as well as decreased transepithelial electrical resistance in Caco-2 cells [19].

Here we report an integrated study of the mechanisms involved in the proximal tubular epithelial cell detachment in response to sublethal ischemia. For that purpose, we have established an in vitro model, using the proximal tubular 
epithelial rat cell line NRK-52E, which includes nutrients and oxygen depletion/repletion and provokes cell shedding. By means of this system, we have demonstrated that cell detachment involves actin cytoskeleton reorganization, Rac1 activation, FAC disassembly and $\mathrm{AJ}$ as well as TJ disruption. In addition, we have determined that oxidative stress is generated during hypoxia and it is responsible for disassembly of FAC components without affecting intercellular unions (AJ or TJ). Moreover, we conclude that FAC impairment was not sufficient to provoke cell detachment, which also required AJ and $\mathrm{TJ}$ disruption. These results show, for the first time, that oxidative stress affects cell-matrix but not cell-cell adhesion as part of proximal epithelial cell response to ischemia.

\section{Material and methods}

\section{Cell culture and $H / R$ in vitro system}

NRK-52E cells (ATCC), mycoplasma free, were cultured in DMEM containing 5\% FBS, $2 \mathrm{mM}$ glutamine, $100 \mathrm{U} / \mathrm{ml}$ penicillin and $100 \mu \mathrm{g} / \mathrm{ml}$ streptomycin (Invitrogen), in a humidified atmosphere with $5 \% \mathrm{CO}_{2}$ at $37^{\circ} \mathrm{C}$. For the in vitro system, confluent cells on collagen IV $(1 \mu \mathrm{g} / \mathrm{ml}$, SIGMA) were made quiescent by serum deprivation for $24 \mathrm{~h}$. Monolayers were cultured for $6 \mathrm{~h}$ in HBSS (Invitrogen) and hypoxic atmosphere $1 \% \mathrm{O}_{2}, 94 \% \mathrm{~N}_{2}, 5 \% \mathrm{CO}_{2}$ (Air liquide) in an hermetic incubator. Then, they were cultured in complete medium and $5 \% \mathrm{CO}_{2}$ for reoxygenation/recovery in a standard incubator. $6 \mathrm{~h}$ of hypoxia was chosen because these conditions induce cell detachment during reoxygenation, without inducing cell death (apoptosis or necrosis). Serum-starved cells subjected to the same changes of medium but not to hypoxia were used as controls for this model: $\mathrm{C}(6 \mathrm{~h})$.

\section{Cell treatments}

As a pro-oxidant treatment, $\mathrm{H}_{2} \mathrm{O}_{2}$ (Merck) $1 \mathrm{mM}$ for 30 min was used. As an antioxidant treatment, NAC $10 \mathrm{mM}$ (SIGMA) during hypoxia (6 h) was used. Antimycin A (SIGMA-Aldrich) $1 \mu \mathrm{M}$ during $30 \mathrm{~min}$ was used as positive control for ATP depletion.

To inhibit Rac1 activity, cells were treated during hypoxia with $50 \mu \mathrm{M}$ of cell permeant NSC23766 (Calbiochem). For RhoA activity inhibition, cells were treated during hypoxia with non cell permeant C3 exoenzyme (Clostridium botulinum) $10 \mu \mathrm{g} / \mathrm{ml}$ (Calbiochem), using the delivery system Pro Trans Reagent (MoBiTec GmbH, Gene Therapy System, Inc., USA), according to the manufacturer's instructions. Alexa488 goat IgG $(10 \mu \mathrm{g} / \mathrm{ml})$ (Invitrogen) combined with delivery reagent was used as positive control for protein delivery method. C3 was applied during hypoxia for technical reasons: C3 delivery is more efficient in medium without serum and requires at least $4 \mathrm{~h}$ of incubation. Rac1 and RhoA inhibition experiments were performed three times.

\section{Intracellular ATP levels}

ATP levels in lysates from cells upon H/R and also cells treated with Antimycin A were determined using the ATP bioluminis- cence CLS kit from Amersham-Pharmacia, following manufacturer's instructions.

\section{Actin cytoskeleton staining and immunofluorescences}

NRK-52E cells were grown on coverslips coated with collagen IV $(1 \mu \mathrm{g} / \mathrm{ml}$, SIGMA-Aldrich). To visualize the actin cytoskeleton, cells were fixed in $3.7 \%$ formaldehyde, permeabilized with $0.5 \%$ Triton X-100, blocked in PBS 1\% BSA and stained with Phalloidin-Alexa568 (50 U=165 nM, Invitrogen). For FAK, p-FAK and paxillin immunofluorescence, cells were processed as above and incubated in PBS 1\% BSA containing anti-FAK 1:50 (Santa Cruz Biotechnologies), anti-p-FAK (Tyr 397) 1:50 (Santa Cruz Biotechnologies) and anti-paxillin 1:50 (Upstate Biotechnologies), followed by the appropriate secondary antibodies: anti-rabbit FITC 1:100 (Jackson ImmunoResearch Laboratories) and anti-mouse Alexa488 1:100 (Invitrogen). For double staining E-cadherin/actin, E-cadherin/ $\beta$-catenin or E-cadherin/ZO-1, cells were fixed in 1:1 methanol/acetone, blocked and incubated in PBS 1\% BSA containing anti-Ecadherin 1:200 (BD Transduction Laboratories), anti-actin 1:50 (Santa Cruz Biotechnologies), anti $\beta$-catenin 1:200 (R\&D System) and anti-ZO-1:200 (Zymed Laboratories), followed by the appropriate secondary antibody: anti-mouse Alexa594 1:100, anti-rabbit Alexa488 1:100 or anti-goat Alexa488 1:200 (all from Invitrogen). After washing, samples were mounted with mowiol (Calbiochem) and observed using a Leica TCSSP2-AOBS-UV confocal inverted microscope. Images and quantifications shown were obtained and processed with Leica Confocal Software. Immunofluorescence experiments were performed at least three times.

\section{Pull down assays and Western blotting}

Cells were lysed in 1\% Triton X-100, 1\% NP-40, 0.25\% sodium deoxycholate, $1 \mathrm{mM}$ DTT with protease inhibitors: $1 \mu \mathrm{g} / \mathrm{ml}$ aprotinin, $1 \mu \mathrm{g} / \mathrm{ml}$ leupeptine, $25 \mathrm{mM}$ AEBSF and phosphatase inhibitors: $25 \mathrm{mM}$ sodium fluoride and $1 \mathrm{mM}$ sodium orthovanadate (all from SIGMA-ALDRICH), during $20 \mathrm{~min}$ at $4^{\circ} \mathrm{C}$. Pre-cleared supernatants were used for pull down assays and/or western blotting. Rac1 and RhoA pull down assays were performed as previously described [20]. Briefly, cell lysates were incubated with $20 \mu \mathrm{g}$ of GST-Pak1 (57-141 aa) or GST-Rottekin (1-89 aa) during $30 \mathrm{~min}$ at $4^{\circ} \mathrm{C}$. GST-Pak and GSTRottekin were previously bound to $4 \mathrm{~B}$ Glutation sepharose beads (Amersham-Pharmacia), as per the manufacturer's instructions. Then, the beads were washed in lysis buffer. Bound Rac-GTP and RhoA-GTP were resolved by 15\% SDSPAGE and determined by immunoblotting, using monoclonal anti-Rac1 (BD transduction laboratories) and polyclonal antiRhoA (Santa Cruz Biotechnology), also used for determining total protein expression.

To determine FAK, p-FAK, paxillin, E-cadherin and $\beta$ catenin expression, we performed $8 \%$ and $10 \%$ SDS PAGE gels (BioRad) transferred to PVDF membranes (BioRad), blotted with the same antibodies used for IF and developed by ECL system (Amersham-Pharmacia). Quantification of ECL signals was performed using Scion Image software.

Cell lysates, from three independent $H / R$ kinetics, were used for pull down assays and western blot. 


\section{Cell detachment quantitation and adhesion assays}

Detached and attached cells after trypsinization were quantified by flow cytometry. Previously, the NRK-52E cell population was labeled with the vital probe BCECF-AM (2',7'-bis-(2carboxyethyl)-5-(and-6)-carboxyfluorescein, acetoxymethyl ester) $1 \mu \mathrm{M}$ during hypoxia.

For adhesion assays, cells submitted to $\mathrm{H} / \mathrm{R}$ were labeled with BCECF-AM $1 \mu \mathrm{M}$ for $30 \mathrm{~min}$ at $37^{\circ} \mathrm{C}$, trypsinized and $1 \times 10^{4}$ cells were allow to attach to collagen IV-coated 96 well plates, for $30 \mathrm{~min}$ at $37^{\circ} \mathrm{C}$. After washing, cells were lysed in PBS containing 10\% SDS and the fluorescent emission was measured at $480 \mathrm{~nm}$ by fluorimetry.

Non-selective monolayer permeability

Confluent cells on transwells coated with collagen IV $(1 \mu \mathrm{g} / \mathrm{ml})$ were submitted to $\mathrm{H} / \mathrm{R}$ and incubated for $15 \mathrm{~min}$ with $1 \%$ trypan blue in culture medium (Invitrogen) at $37^{\circ} \mathrm{C}$. Epithelial barrier integrity was estimated measuring the amount of trypan blue contained in the recovered lower chamber medium, by spectrometry at $595 \mathrm{~nm}$.

\section{ROS production}

Cells submitted to $H / R$ were labeled with $H_{2}$-DCFDA $\left(2^{\prime}, 7^{\prime}\right.$ dichlorodihydrofluorescein diacetate) $5 \mu \mathrm{M}$ or DHR (Dihydror- odamine) $5 \mu \mathrm{M}$, for $6 \mathrm{~h}$ at $37^{\circ} \mathrm{C}$ in HBSS without phenol red. Then, cells were trypsinized, washed and resuspended in PBS. Fluorescent emission was quantified by flow cytometry (FACScan cytometer, BD) and the results were analyzed using WinMD software.

ROS generation was estimated in three independent experiments for each probe.

\section{Statistical analysis}

Statistical significance of experimental differences was estimated by ANOVA and Student's t test using Prism software (GraphPad, Inc.). P value $<0.05$ was considered to be significant.

\section{Results}

Proximal tubule epithelial cells detach in response to sublethal ischemia

As we previously reported, sublethal renal ischemia of $45 \mathrm{~min}$ followed by reperfusion induces proximal tubular epithelial cell detachment in rats, which is maximum at $24 \mathrm{~h}$ [10]. To explore the mechanisms involved, we have established an in vitro model using NRK-52E proximal tubular cells, which entails changes in nutrient and oxygen availability (described on Material and methods). For simplicity,
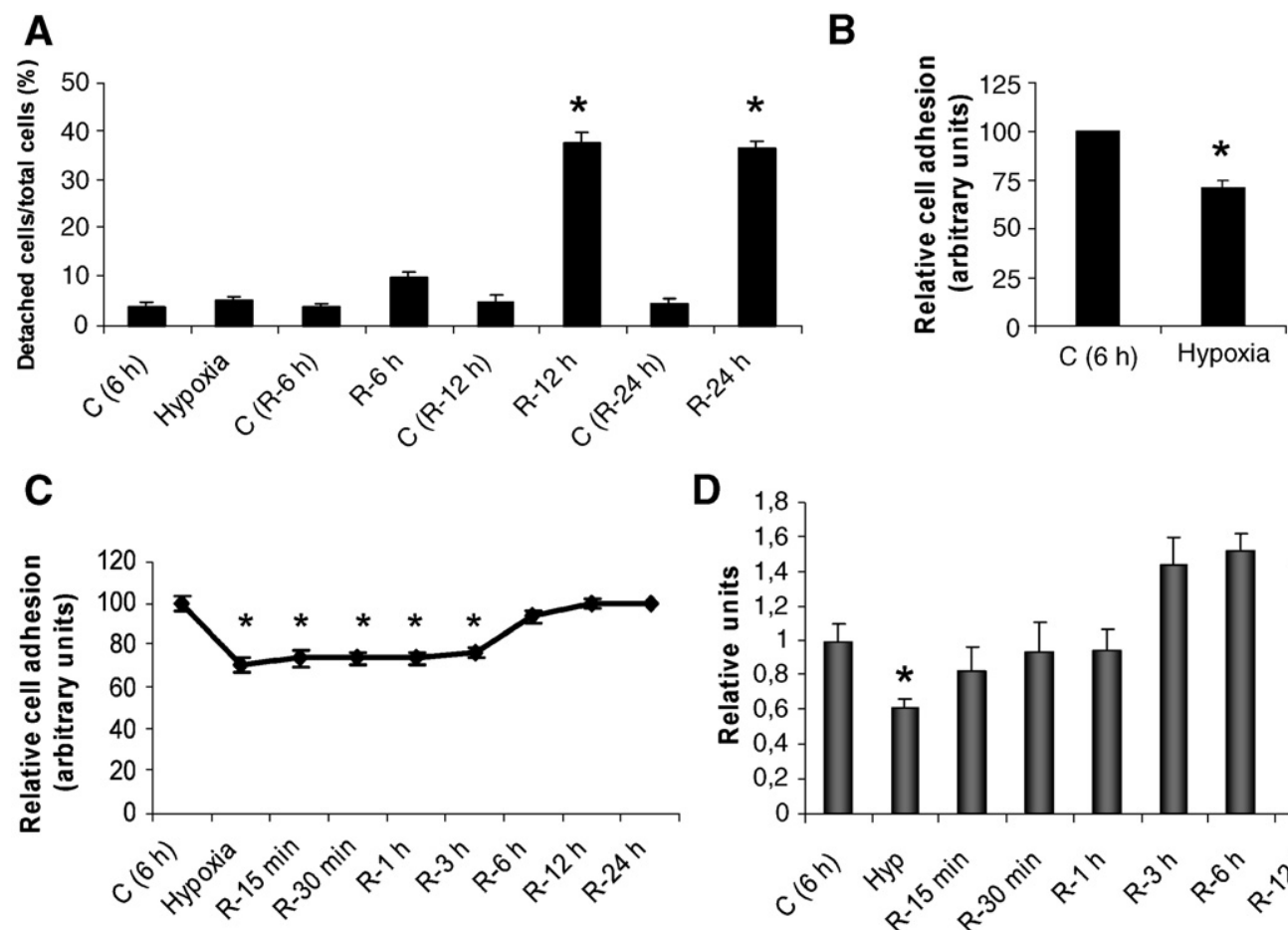

$$
2^{n}
$$

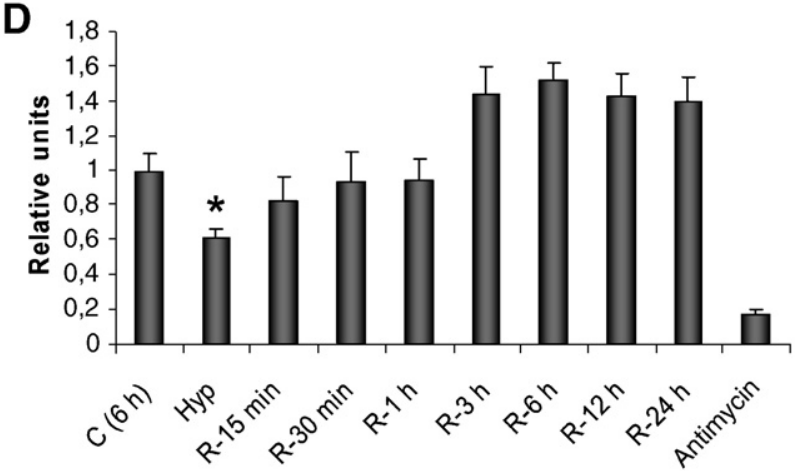

Fig. 1 - H/R in vitro induces loss of NRK-52E cell adhesion and ATP depletion. (A) Ratio of detached/total cells under H/R, previously labeled with BCECF-AM, estimated by flow cytometry. (B) Cell adhesion to collagen IV matrix after hypoxia and different times of reoxygenation, was estimated measuring fluorescence in cell lysates by fluorimetry, previously labeling the cells with BCECF-AM. (D) Relative intracellular ATP levels in cells submitted to H/R, estimated by bioluminescence in whole cell lysates, using a fluorimeter. Signal corresponding to C (6 h) was considered as 1 and treatment with Antymicin A was used as positive control for ATP depletion. In all graphs, data are represented as mean \pm SEM for four independent experiments. ${ }^{*} P<0.01$ comparing with $\mathrm{C}(6 \mathrm{~h})$ except in panel $\mathrm{A}$ in which they are compared with their respective controls $\mathrm{C}$ (R-12 h) and C (R-24 h). 
A
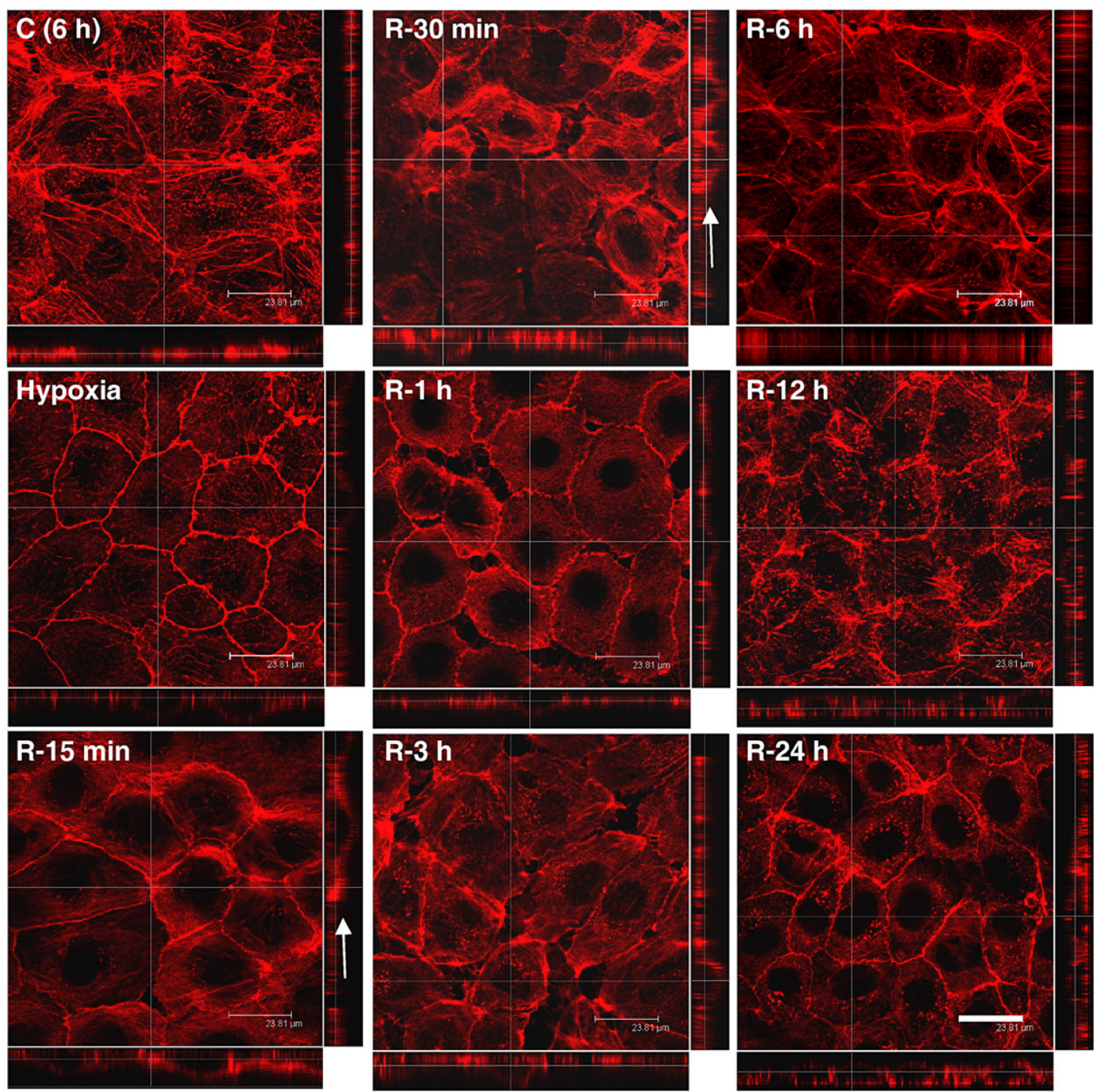

B

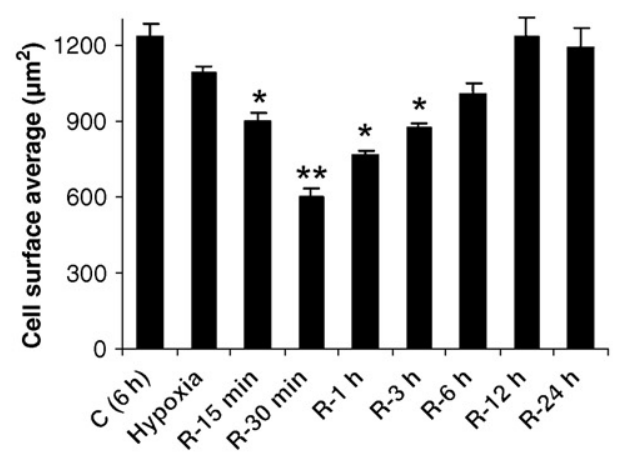

C

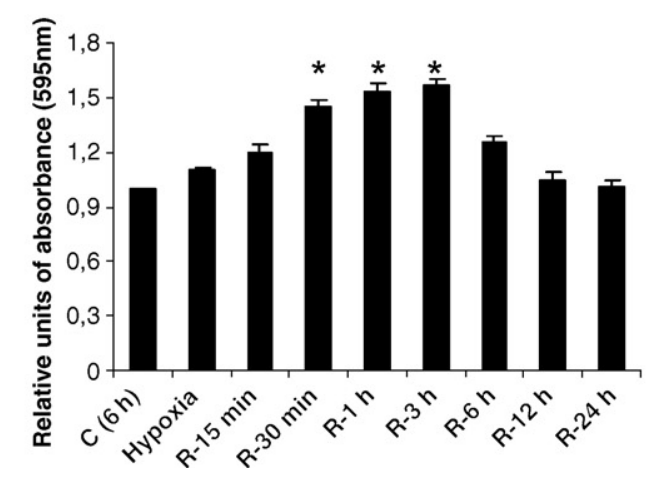

Fig. 2 - Effects of H/R on actin cytoskeleton organization, cell size and monolayer integrity. (A) Representative confocal microscopy images (maximum projections) of phalloidin staining showing actin cytoskeleton reorganization, cell contraction and cell protrusion, during the $\mathrm{H} / \mathrm{R}$ protocol. Protruding cells are indicated by arrows in the orthogonal projections. Additionally, loss of monolayer integrity is evidenced by the increasing intercellular gaps at reoxygenation time points (15 min-6 $\mathrm{h}$ ). Scale bar: $23.81 \mu \mathrm{m}$ (B). Cell surface quantification of 10 cells from each one of 5 different fields from each condition, expressed on $\mu^{2}{ }^{2}$, was calculated using Leica Lite Confocal Software. Data are represented as mean \pm SEM from three independent experiments. ${ }^{*} P<0.05 ;{ }^{* *} P<0.01$ comparing with $\mathrm{C}(6 \mathrm{~h})$. (C) Epithelial monolayer permeability, using transwell, was estimated after monolayer incubation with trypan blue, by determining the absorbance of lower chamber medium at $595 \mathrm{~nm}$. Data are represented as mean \pm SEM from four independent experiments. ${ }^{*} P<0.01$ comparing with $C(6 \mathrm{~h})$. 
we refer to this model as hypoxia/reoxygenation (H/R) even though it involves both oxygen and nutrient alterations.

To estimate the degree of cell detachment induced by $H / R$, we quantified detached cells by flow cytometry. Fig. 1A shows that NRK-52E submitted to hypoxia detached significantly during the following $12-24 \mathrm{~h}$ of reoxygenation in comparison to control cells. No significant differences in the total number of cells among all the conditions were found. Additionally, we have performed adhesion assays to study alterations in the capacity of NRK-52E cells submitted to H/R to attach on
A

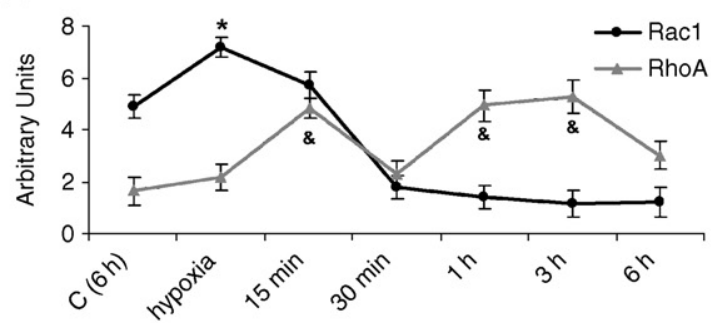

B
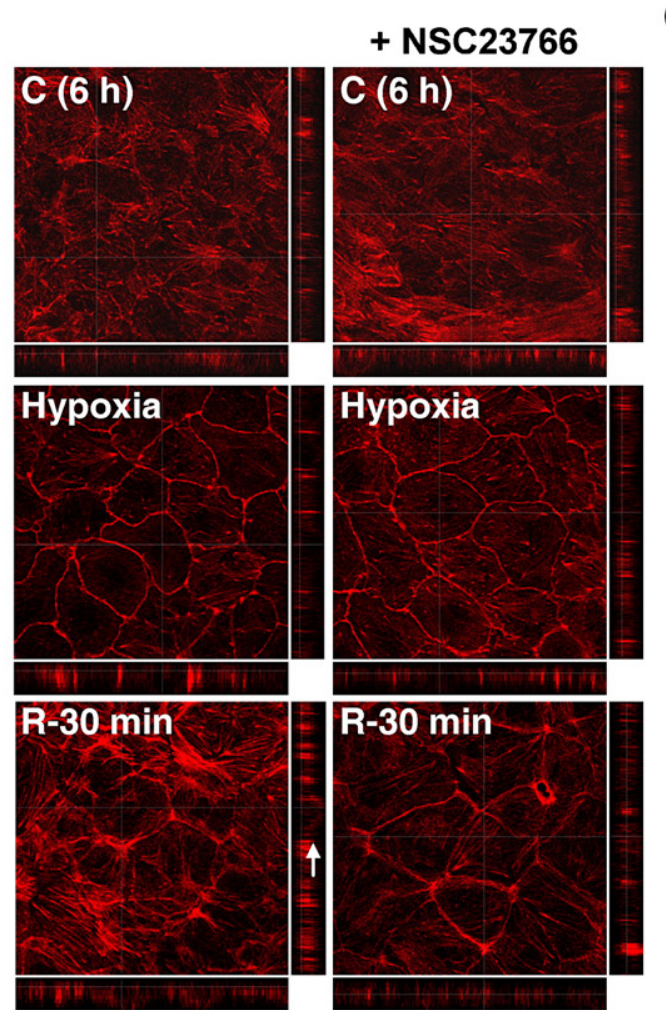

D

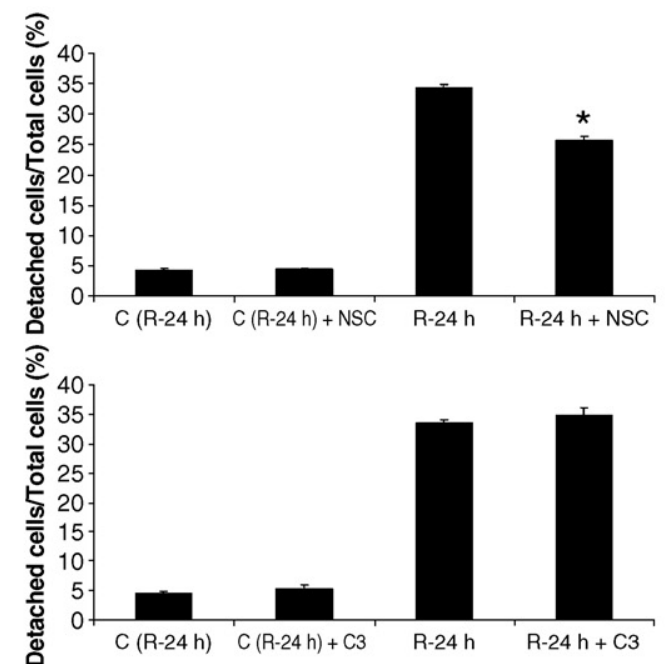

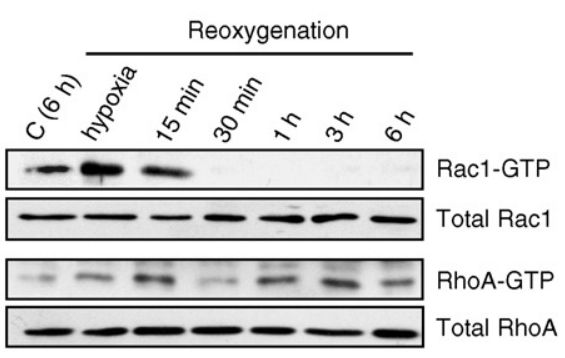

C

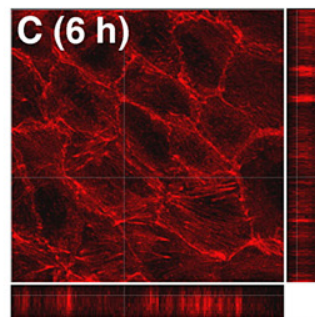

$+\mathrm{C} 3$
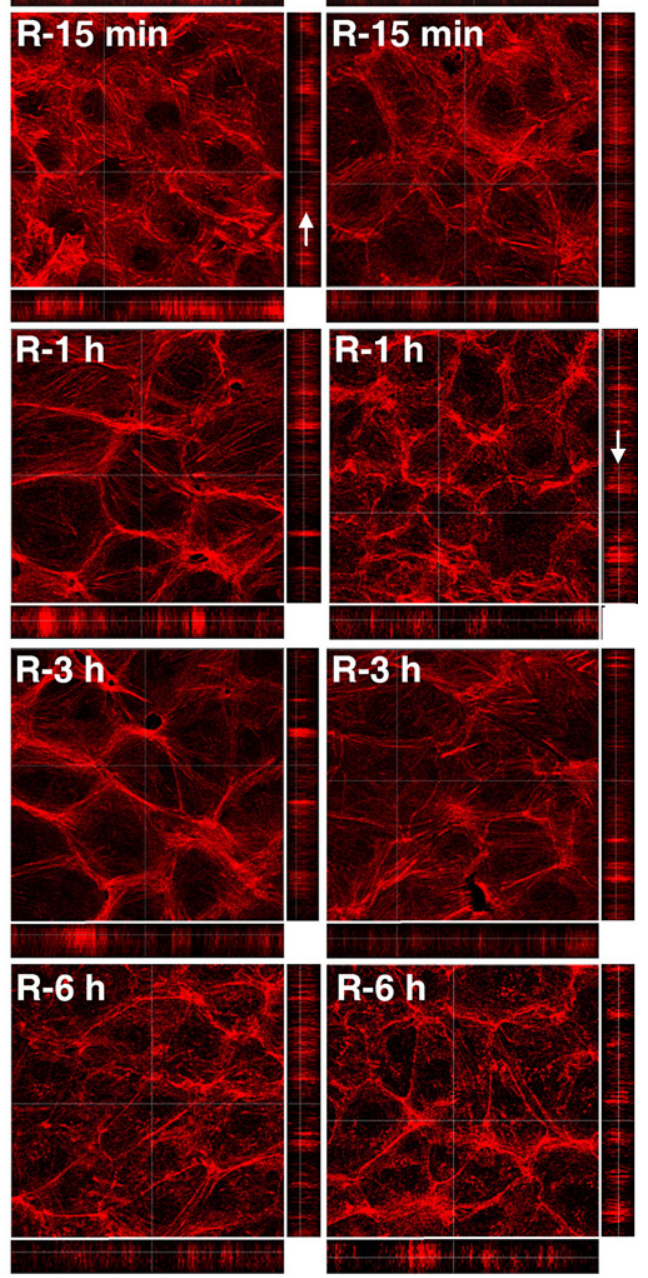
collagen IV. Hypoxia by itself reduced adhesion by $30 \%$, in comparison to the control (Fig. 1B). The capacity of NRK-52E cells to adhere to collagen IV was completely restored after $12 \mathrm{~h}$ of reoxygenation, when the percentage of detached cells reached the maximum (Fig. 1B).

Additionally, hypoxia induced a significant but moderate decrease in intracellular ATP levels (Fig. 1C) which rapidly recovered during the reoxygenation phase, with several implications as we will discuss later. Antimycin A, used as a control, induced a pronounced ATP depletion. H/R-induced alterations in ATP levels did not result in significant apoptosis or necrosis, in contrast to Antimycin A treatment [54]. These results indicate that this in vitro system could be used to study mechanisms involved in the proximal epithelial cell response to sublethal renal ischemia in vivo, since the H/R protocol established induces primarily the loss of NRK-52E cell adhesion, not loss of cell viability.

$\mathrm{H} / \mathrm{R}$ induces actin cytoskeleton reorganization, cell contraction and loss of monolayer integrity in NRK-52E cells

The loss of adhesion implies significant changes in epithelial cell morphology and monolayer integrity. In order to explore both aspects, we have used phalloidin staining and confocal microscopy to monitor the changes in F-actin induced by $\mathrm{H} / \mathrm{R}$. As it can be observed in Fig. 2A, hypoxia induced the disappearance of stress fibers, although cortical actin remained well organized. However, staining for both cortical actin and stress fibers was significantly reduced during the early times of reoxygenation (15 min to $3 \mathrm{~h}$ ), as compared with control, indicating actin depolymerization. Orthogonal projections showed that several cells lost contact with the substrate and protruded upwards without detaching completely from the plate (indicated by arrows). This phenomenon, which we called cell protrusion, started during hypoxia and continued during very early times of reoxygenation, being more evident at $30 \mathrm{~min}$. At $12 \mathrm{~h}$ of reoxygenation, the cytoskeleton organization resembles the control condition.

Reoxygenation was also accompanied by an evident decrease in the cell surface, which was indicative of cell contraction. Quantification of this effect is shown in Fig. 2B. The planar cell surface area was reduced significantly during early times of reoxygenation (15 min-3 h), in comparison with control cells $\mathrm{C}(6 \mathrm{~h})$, being minimal at $30 \mathrm{~min}$ and coinciding with the time of maximal cell protrusion. Again, at $12 \mathrm{~h}$ of reoxygenation, cell surface was restored.
On the other hand, cell contraction resulted in loss of the monolayer integrity, since at early times of reoxygenation (30 min-3 h), the intercellular contacts appeared disrupted at several sites with the appearance of gaps between cells. To assess the functional consequences of these morphological changes, we quantified the epithelial barrier permeability. Trypan blue dye added on top of the monolayer in a transwell was recovered from the lower chamber in higher amounts at early times of reoxygenation ( $30 \mathrm{~min}-3 \mathrm{~h}$ ) (Fig. 2C), thus showing a transient increase in epithelial barrier permeability, which was coincident with the visual observations of monolayer integrity interruption. Epithelial barrier integrity was completely restored at $12 \mathrm{~h}$.

The phenomena described above correlate with the loss of adhesion to collagen IV under H/R, described on Fig. 1. Moreover, all these alterations were restored at $12 \mathrm{~h}$ when the cell detachment did not increase any longer.

$H / R$ induces changes in Rac1 and RhoA activity correlating with actin cytoskeleton reorganizations in NRK-52E cells

Actin cytoskeleton dynamics is regulated, among other factors, by the activity of Rho GTPases. Cortical actin structure and stress fibers formation involve the activity of Rac1 and RhoA. Because $\mathrm{H} / \mathrm{R}$ induced actin cytoskeleton alterations in NRK-52E cells, we have measured the activity of endogenous Rac1 and RhoA in these conditions, by performing pull down assays. As it is shown in Fig. 3A, hypoxia induced an increase in Rac1 activity. However, during reoxygenation Rac1 activity decreased markedly, even below the detection levels of this assay. RhoA activity showed a biphasic pattern with a slight increase during hypoxia, much more marked at 15 min of reoxygenation, and followed by a second peak between 1 and $3 \mathrm{~h}$. The total levels of Rac1 and RhoA proteins did not show significant changes.

These results indicate that $H / R$ experimental conditions induce marked alterations in the activity of endogenous Rac1 and RhoA which may be involved in the actin cytoskeleton reorganization associated with NRK-52E cell detachment. To asses this issue, cells were treated with NSC23766 $50 \mu \mathrm{M}$ and C3 exoenzyme $10 \mu \mathrm{g} / \mathrm{ml}$, specific inhibitors of each activity respectively. These concentrations have been reported to inhibit Rac1 and RhoA activities efficiently [51,52].

As is shown in Fig. 3B, the presence of the Rac1 inhibitor NSC23766 during hypoxia reduced cell body contraction and cell protrusion at very early times of reoxygenation $(30 \mathrm{~min})$, observable by F-actin staining and confocal microscopy

Fig. 3 - H/R induces changes in endogenous Rac1 and RhoA activities in NRK-52E cells. Effects of specific Rac1 inhibitor NSC23766 and specific RhoA inhibitor C3 exoenzyme. (A) Rac1-GTP and RhoA-GTP levels determined by pull-down assay and total Rac1 and RhoA levels determined by western blot, representative assay is shown. Quantification of the relative levels of the above mentioned active forms by densitometry, corrected by the total levels of expression of both proteins, means \pm SEM of three independent experiments are shown. ${ }^{*} P<0.01$ comparing to $C(6 \mathrm{~h}) ;{ }^{8} P<0.01$ comparing with $\mathrm{C}(6 \mathrm{~h})$. Representative confocal microscopy images (maximum projections) of phalloidin staining showing actin cytoskeleton reorganization, cell contraction and cell protrusion, during the H/R protocol in the presence or absence of $50 \mu \mathrm{M} \mathrm{NSC23766} \mathrm{during} \mathrm{hypoxia} \mathrm{(B)} \mathrm{and}$ C3 exoenzyme (Clostridium botulinum) $10 \mu \mathrm{g} / \mathrm{ml}$ added during hypoxia (C). Protruding cells are indicated by arrows in the orthogonal projections. Alterations in monolayer integrity are evidenced by the appearance of intercellular gaps. Scale bar: $23.81 \mu \mathrm{m}$. Ratio of detached/total cells at $24 \mathrm{~h}$ of reoxygenation, estimated by flow cytometry, in the presence or absence of $50 \mu \mathrm{M}$ NSC23766 (D) and C3 exoenzyme $10 \mu \mathrm{g} / \mathrm{ml}$ (E); cells were previously labeled with BCECF-AM. ${ }^{*} P<0.01$ comparing to R-24 h without inhibitor. 
analysis. This result correlates with the significant reduction in cell detachment at $24 \mathrm{~h}$ of reoxygenation observed in those cells treated with NSC23766 during hypoxia (Fig. 3D).
On the other hand, as shown in Fig. 3C, NRK-52E cells treated with the RhoA specific inhibitor C3 exoenzyme exhibit reduced cell contraction and protrusion at very early
A
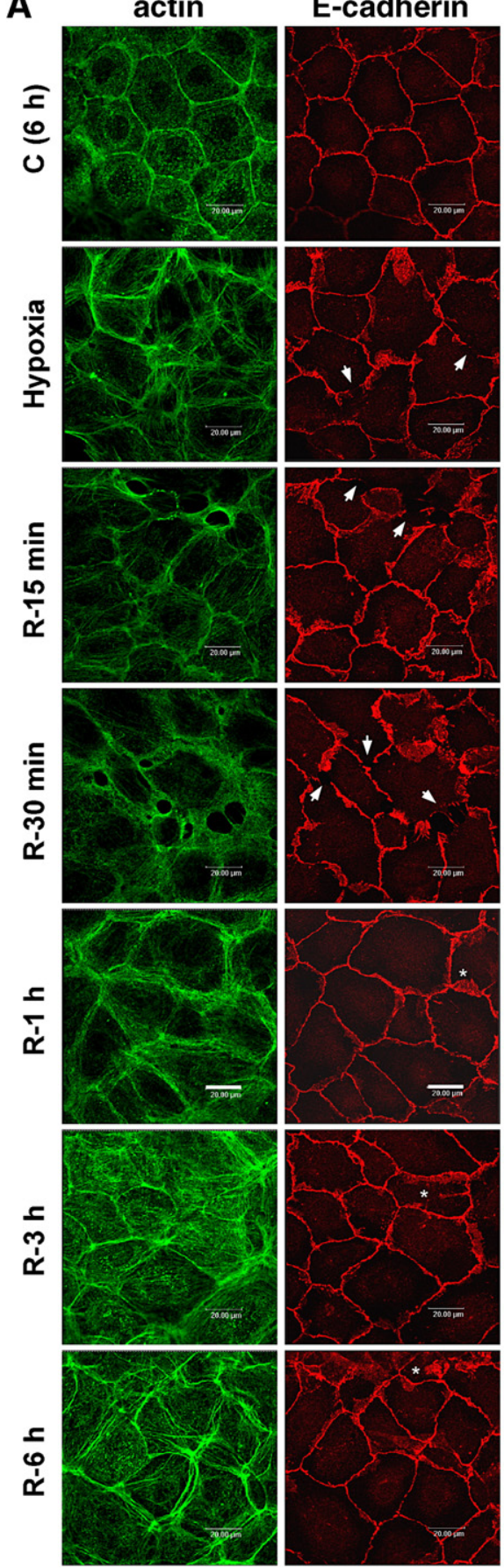
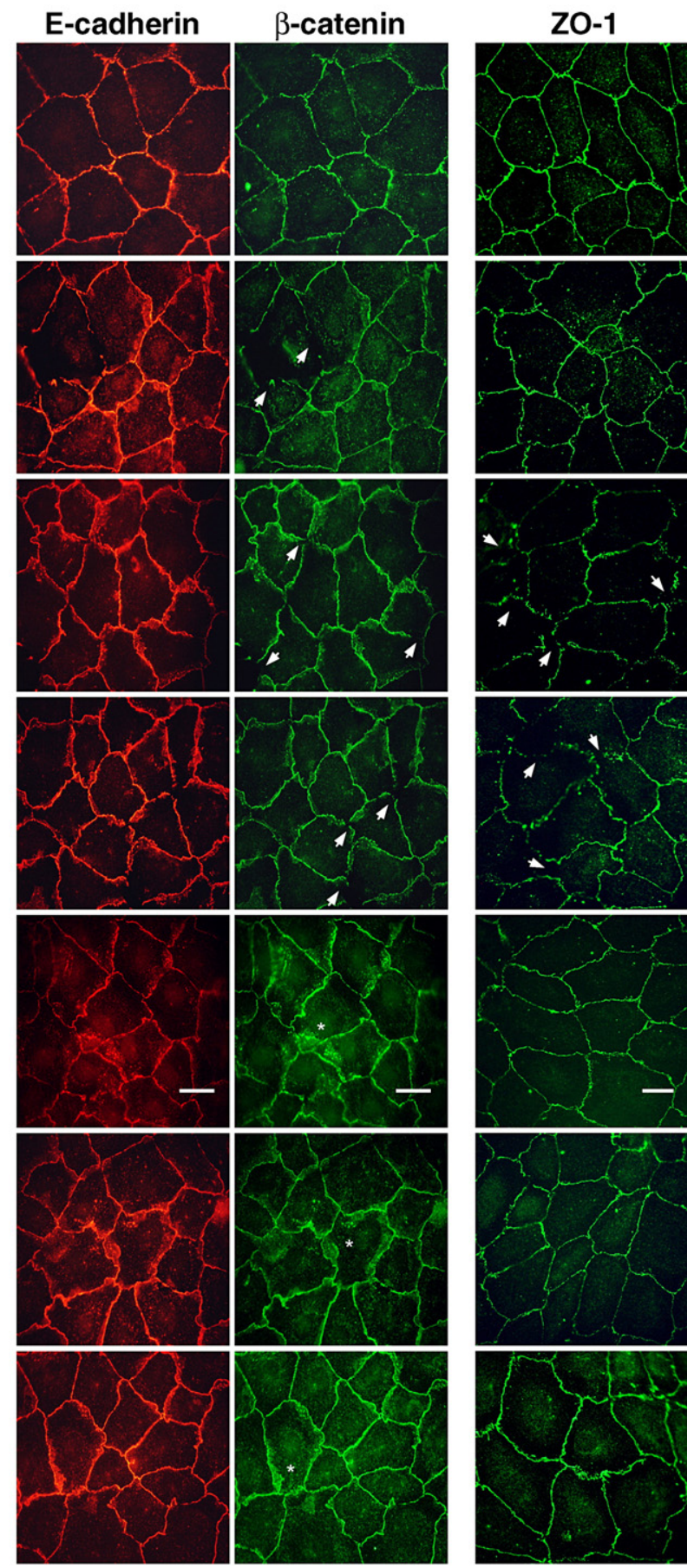

B

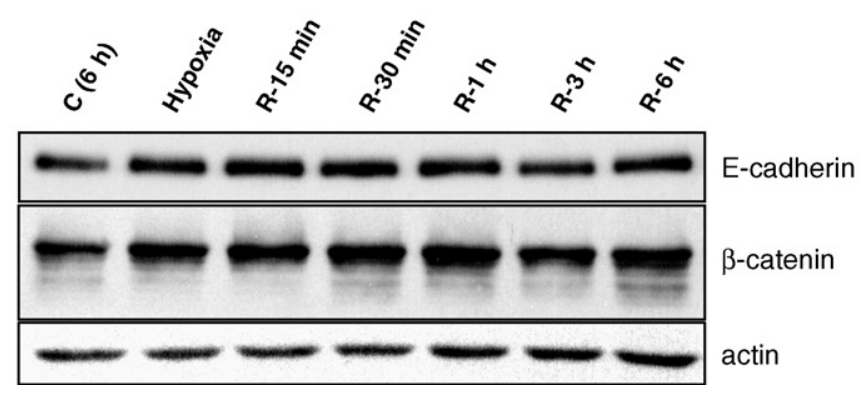


times of reoxygenation (15 $\mathrm{min}$ ) but a significant increase in both phenomena at $1 \mathrm{~h}$ of reoxygenation. At $6 \mathrm{~h}$, the cytoskeleton organization and monolayer structure resemble the conditions without inhibitor, as estimated by phalloidin staining and confocal microscopy analysis. Cell detachment at $24 \mathrm{~h}$ of reoxygenation in the presence of $\mathrm{C} 3$, estimated by flow cytometry, did not show significant differences with respect to untreated cells detachment. As it was expected, C3 by itself reduced stress fibers in control $(\mathrm{C}(6 \mathrm{~h})+\mathrm{C} 3)$.

Taken together, these results indicate that alterations in actin cytoskeleton organization, cell size and cell detachment observed in NRK-52E cells submitted to H/R correlate with alterations in Rac1 and RhoA activities.

$H / R$ induces transitory disruption of adherens and tight junctions in NRK-52E cells

As described above, $\mathrm{H} / \mathrm{R}$ leads to the appearance of intercellular gaps and loss of monolayer integrity. To get further insight into the mechanisms responsible for these processes, we studied whether the structures involved in cell-cell adhesion were affected under our experimental conditions. We explored the distribution of endogenous AJ components, including Ecadherin and $\beta$-catenin, as well as actin organization, by inmunofluorescence. As it can be observed in Fig. 4A, Ecadherin was distributed continuously along the membrane in control cells, co-localizing with cortical actin at the sites of intercellular contacts. However, this pattern was lost during hypoxia and very early times of reoxygenation (15 min-1 h), coinciding with the loss of monolayer integrity. Moreover, Ecadherin staining suffered redistribution towards the cytoplasmic region underneath the cell membrane, at the sites of disrupted cellular contacts. Interestingly, continuous E-cadherin membrane staining is recovered after $1 \mathrm{~h}$ of reoxygenation. Late in the reoxygenation phase (6-12 h), E-cadherin staining completely resembled the control situation. In this set of experiments, the distribution of actin was explored by means of an anti-actin antibody. It is important to note that staining with this antibody confirmed the occurrence of cellular contraction as well as the loss of monolayer integrity observed with phalloidin staining (Fig. 2). Correlative alterations were observed in the distribution of $\beta$-catenin: removal from the membrane during hypoxia and very early times of reoxygenation (15 $\mathrm{min}-1 \mathrm{~h}$ ) and recovery of the control pattern from $6 \mathrm{~h}$ (Fig. 4A).

Although continuous E-cadherin/ $\beta$-catenin staining between contiguous cells appears recovered at $1 \mathrm{~h}$, significant cytoplasmic staining near the plasma membrane is still observed until $6 \mathrm{~h}$ of reoxygenation (indicated by asterisks). In any case, E-cadherin and $\beta$-catenin removal was not due to specific degradation of these proteins, as we have confirmed by western blot (Fig. 4B).
Additionally, we have also analyzed the integrity of the TJ, which assure epithelial barrier impermeability and are compromised when AJ alterations occur, performing ZO-1 immunofluorescence. As it can be observed in Fig. 4A, ZO-1 was continuously distributed along the plasma membrane in control cells and during hypoxia. Correlating with E-cadherin alterations, ZO-1 staining was disrupted at very early times of reoxygenation (15 $\min -1 \mathrm{~h})$. Late in the reoxygenation $(6 \mathrm{~h})$, the distribution of ZO-1 resembles that of control cells.

These results suggest that the transient disruption in the distribution of E-cadherin/ $\beta$-catenin complexes and ZO-1 protein along the membrane plays a role in the loss of monolayer epithelial integrity, in the alteration of the epithelial barrier function and may also contribute to epithelial cell detachment.

$H / R$ induces transient disruption of focal adhesion complexes in NRK-52E cells

FAC mediate cell adhesion to the substrate requiring the assembly of multiple components. Because H/R experimental conditions induce loss of NRK-52E cell adhesion to collagen IV, we explored the localization of several endogenous components of FAC, i.e., actin stress fibbers, paxillin and p-FAK, in cells subjected to $\mathrm{H} / \mathrm{R}$, by phalloidin staining, immunofluorescence and confocal microscopy. As it can be observed in Fig. $5 \mathrm{~A}$, control cells showed co-localization of actin stress fibers and paxillin. This pattern was lost during hypoxia and early times of reoxygenation ( $15 \mathrm{~min}-3 \mathrm{~h}$ ), being restored at $6 \mathrm{~h}$ of reoxygenation. Higher magnification of $C(6 h)$ and R- $6 \mathrm{~h}$ images showing this co-localization are also presented (i; ii). Western blot analysis showed that paxillin levels were not significantly affected by H/R (Fig. 5A).

Additionally, $\mathrm{H} / \mathrm{R}$ altered the distribution of p-FAK (see Fig. 5B). Co-localization of p-FAK and actin stress fibbers was lost during very early times of reoxygenation (15 min-1 h) and recovered at $3 \mathrm{~h}$, without remarkable changes in total FAK distribution (data not shown). Western blot analysis showed that p-FAK was dephosphorylated during hypoxia and very early times of reoxygenation (15-30 min) (Fig. 5B) coinciding with the diminished immunostaining and mis-location of the protein from FAC. However, total FAK levels did not change significantly, as estimated by western blot. Quantification of FAK phosphorylation levels relative to total FAK expression is also shown (Fig. 5B).

Taken together all these results show that H/R induces a reversible disassembly of FAC components in NRK-52E cells, leading to transient FAC disruption. These alterations may play a key role in the cell detachment induced by $H / R$.

ROS are generated during deprivation phase in NRK-52E cells

In many experimental systems, alterations in oxygen and nutrients are associated with oxidative stress generation. We

Fig. 4 - Transient disruption of AJ and TJ induced by H/R. (A) AJ integrity was determined by immunofluorescence of E-cadherin, $\beta$-catenin, ZO-1 and actin immunostaining, visualized by confocal microscopy. The representative confocal images shown were taken at the level of the AJ or TJ. Scale bars: $20 \mu \mathrm{m}$. A transient disruption of the distribution along the membrane of all these proteins, during hypoxia and very early times of reoxygenation ( $15 \mathrm{~min}-1 \mathrm{~h}$ ), marked by arrowheads, is observed. Marked E-cadherin and $\beta$-catenin cytoplasmic staining near to plasma membrane (1-6 h) is marked by asterisks. (B) No significant changes in E-cadherin or $\beta$-catenin protein levels relative to actin were observed by western blot. 
have measured ROS production in NRK-52E cells submitted to $\mathrm{H} / \mathrm{R}$ by flow cytometry, using $\mathrm{H}_{2}$-DCFDA and DHR. Interestingly, as observed in Fig. $6 \mathrm{~A}$ and Fig. $6 \mathrm{~B}$, there is a significant increase in the generation of ROS occurred during hypoxia, returning to basal levels [C $(6 \mathrm{~h})$ ] between $30 \mathrm{~min}$ and $1 \mathrm{~h}$ of reoxygenation. Treatment of NRK-52E cells with $1 \mathrm{mM} \mathrm{H}_{2} \mathrm{O}_{2}$ for 30 min was used as a positive control for ROS generation in both cases.
A
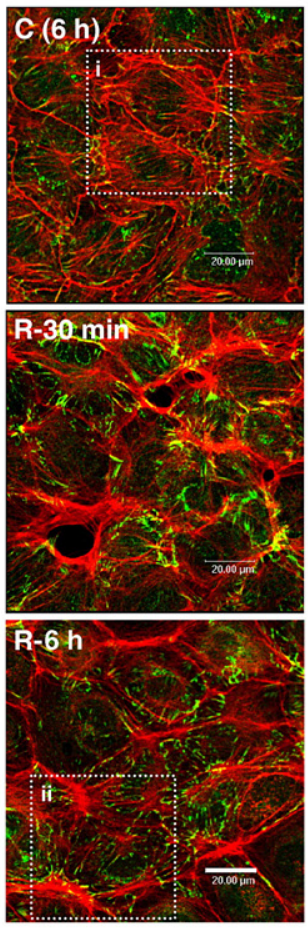

B
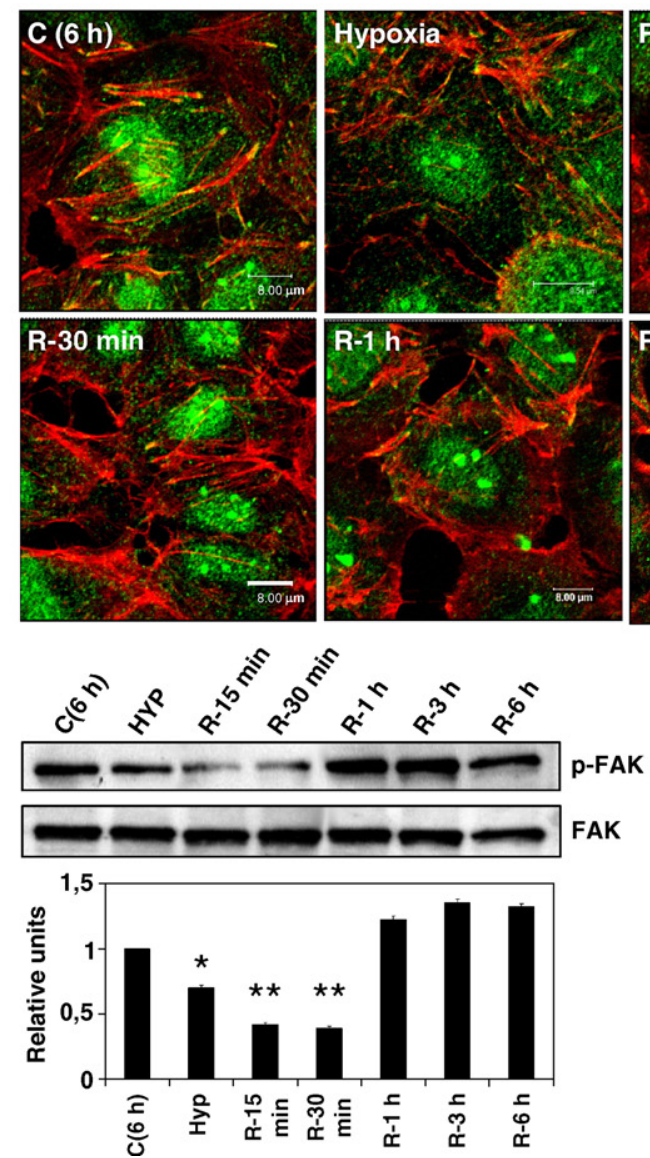
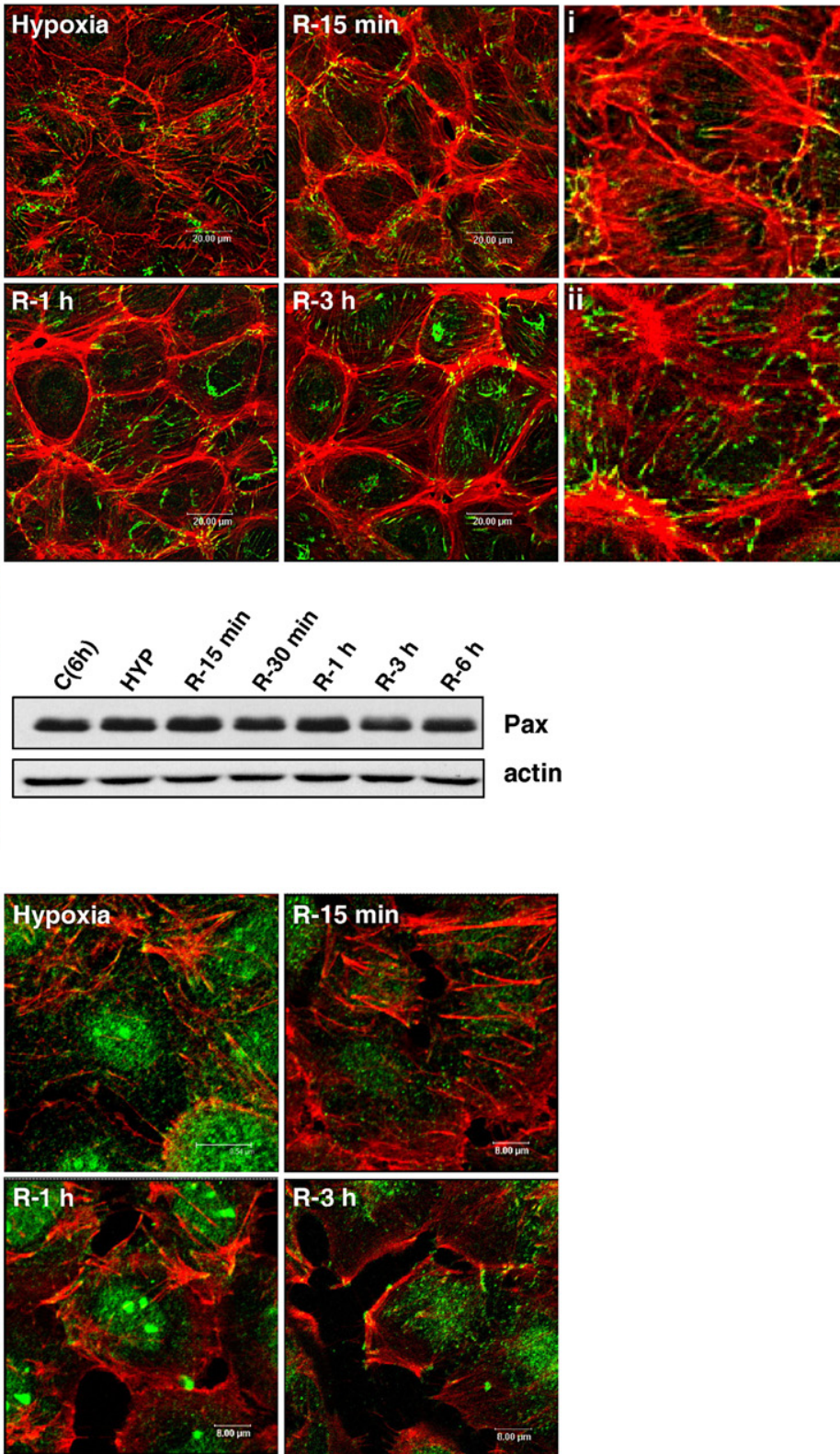

actin
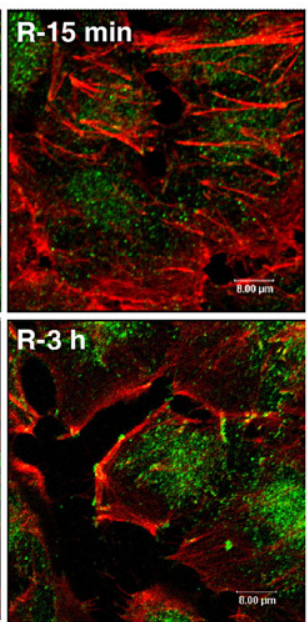
A
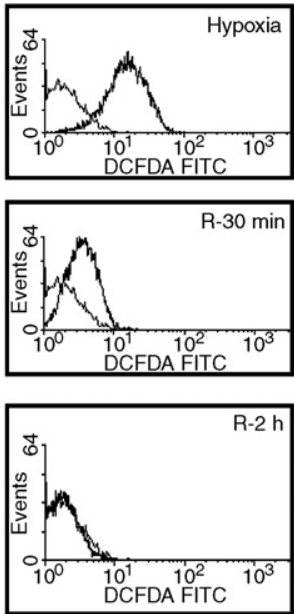

B
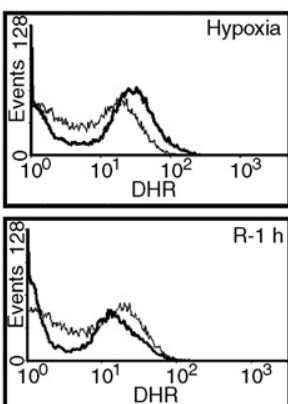
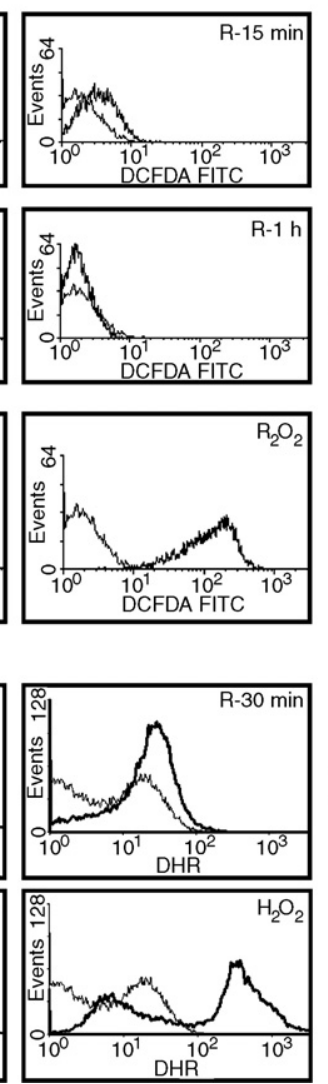

C

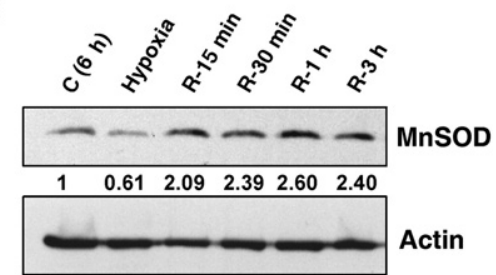

D

\begin{tabular}{|lc|}
\hline $\mathrm{C}(6 \mathrm{~h})$ & 1.00 \\
$\mathrm{C}(6 \mathrm{~h})+\mathrm{NAC}$ & $0.72 \pm 0.5$ \\
Hypoxia & $42.25 \pm 2$ \\
Hypoxia + NAC & $25.35 \pm 2$ \\
$\mathrm{R}-30 \mathrm{~min}$ & $1.06 \pm 0.5$ \\
$\mathrm{R}-30 \mathrm{~min}+\mathrm{NAC}$ & $0.75 \pm 0.5$ \\
$\mathrm{R}-1 \mathrm{~h}$ & $0.92 \pm 0.5$ \\
$\mathrm{R}-1 \mathrm{~h}+\mathrm{NAC}$ & $0.68 \pm 0.5$ \\
$\mathrm{H}_{2} \mathrm{O}_{2}$ & $97.00 \pm 3$ \\
$\mathrm{H}_{2} \mathrm{O}_{2}+\mathrm{NAC}$ & $53.00 \pm 3$ \\
\hline
\end{tabular}

E

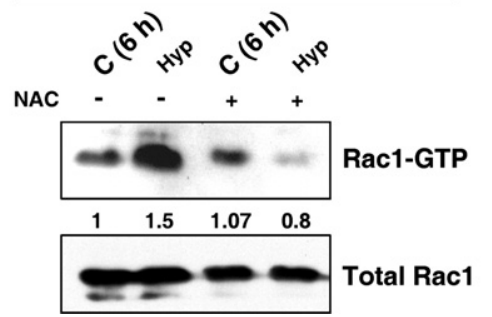

Fig. 6 - Oxidative stress is generated during hypoxic/starvation phase and activates Rac1 in NRK-52E cells. MnSOD expression under $\mathrm{H} / \mathrm{R}$. ROS generation was determined by flow cytometry, using $\mathrm{H}_{2}$-DCFDA in panel A and DHR in panel B, in cells submitted to $\mathrm{H} / \mathrm{R}$. ROS were generated during hypoxia and rapidly scavenged. $\mathrm{H}_{2} \mathrm{O}_{2} 1 \mathrm{mM}$ was used as positive control for both probes. (C) Representative image of the transient induction during reoxygenation of MnSOD expression, determined by western blot. Quantification of MnSOD expression levels relatives to actin is also shown. (D) Percentage of positive cells for ROS generation, in the presence or absence of NAC, estimated by flow cytometry, using $\mathrm{H}_{2}$-DCFDA. Data from three independent experiments are presented as mean \pm SEM. Notice that NAC reduce ROS production significantly. (E) Representative pull down assay to determine Rac1 activity in the presence or absence of NAC, showing that Rac1 activation is dependent on ROS generation. Quantification of the ratio Rac1-GTP/total Rac1 is also shown.

ROS generated during hypoxia correlates with a decrease on MnSOD expression and the quick ROS scavenging observed early during reoxygenation with an induction of these enzyme (15 min-3 h), estimated by western blot (Fig. 6C). Quantification of MnSOD expression relative to actin is also shown. On the other hand, the addition of $10 \mathrm{mM} \mathrm{N}$-acetylcysteine (NAC) during hypoxia also reduced significantly (40\%) the ROS generated. The effect of NAC on ROS generation was assessed using both $\mathrm{H}_{2}$-DCFDA and DHR, and the quantification correspondent to $\mathrm{H}_{2}$-DCFDA used is shown in Fig. 6D.
Since Rac1 could be the cause or the consequence of ROS generation depending on the cell system, to clarify this issue in our $\mathrm{H} / \mathrm{R}$ model, we have measured Rac1 activity in the presence of NAC, performing pull down assays. As it can be observed in Fig. 6E, NAC treatment during hypoxia abrogates Rac1 activation. Quantification of Rac1 activity is also shown in this figure.

All these results indicate that, in NRK-52E cells submitted to $\mathrm{H} / \mathrm{R}, \mathrm{ROS}$ are generated during hypoxia and quickly scavenged because of MnSOD induction among others mechanisms.

Fig. 5 - H/R induces transient disassembly of FAC in NRK-52E cells. FAC components disassembly was evidenced by (A) the mislocalization of paxillin (green) and stress fibers (red), (B) the mislocalization of p-FAK and stress fibers, visualized by immunofluorescence, phalloidin staining and confocal microscopy, during hypoxia and early times of reoxygenation (15 min-1 h-3 h). The representative confocal images shown were taken at the level of the focal adhesion contacts. Scale bars: (A) $20 \mu \mathrm{m}$, (B) C (6 h) $9.54 \mu \mathrm{m}$, rest $8 \mu \mathrm{m}$. Higher magnification of fields from C (6 h) and R-6 images are presented on the right (i; ii). No significant changes in paxillin expression in comparison to actin were observed by western blot (A). p-FAK and total FAK protein levels were also determined by western blot (B), reveling transient dephosphorylation of FAK during hypoxia and very early times of reoxygenation (15-30 min). Quantification of p-FAK vs. total FAK of three independent experiments expressed as mean \pm SEM is also shown. ${ }^{*} P<0.05 ;{ }^{* *} P<0.01$ comparing with $\mathrm{C}(6 \mathrm{~h})$. 
Additionally, ROS are mediating the hypoxia-induced Rac1 activation reported here.

ROS generated during hypoxia are responsible for FAC disruption but do not affect AJ neither TJ

To elucidate the involvement of ROS generated during hypoxia in NRK-52E cell detachment, we have studied the effects of
NAC in our model, determining changes in actin cytoskeleton organization, in focal adhesion and intercellular adhesion integrity and finally, in cell detachment. NAC $10 \mathrm{mM}$ was applied only during hypoxia and the results are shown on Fig. 7. The presence of NAC during this phase abolished the alterations in stress fiber formation and paxillin/actin colocalization in the focal complexes, observed during very early times of reoxygenation ( $15 \mathrm{~min}-1 \mathrm{~h}$ ) (Fig. 7A). Additionally, the
A
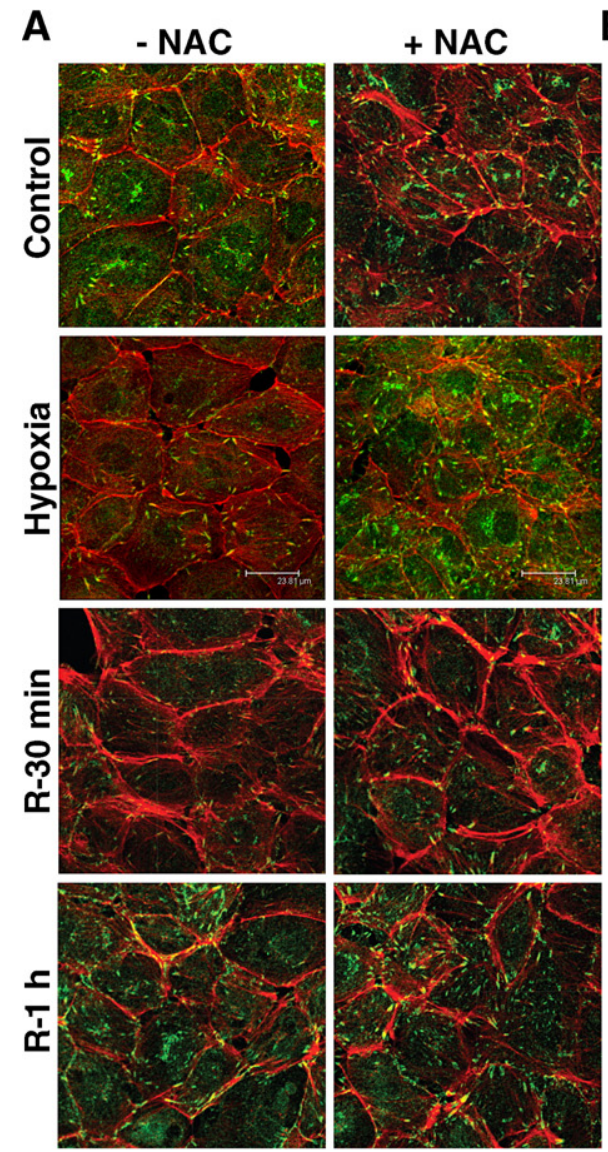

D

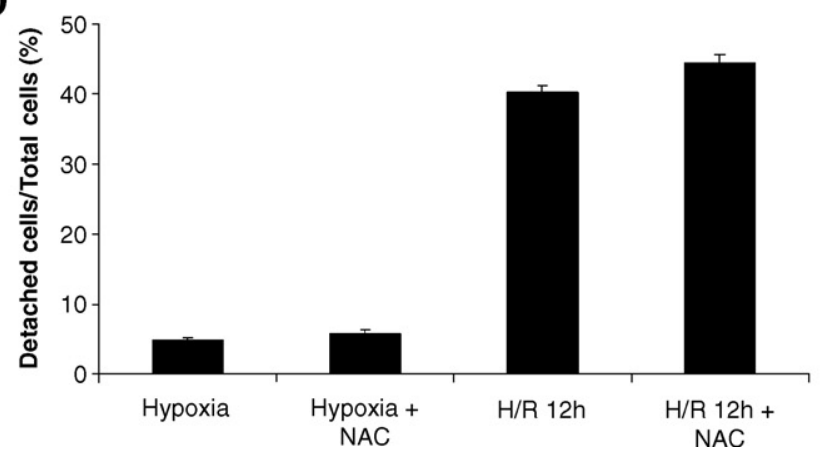

B
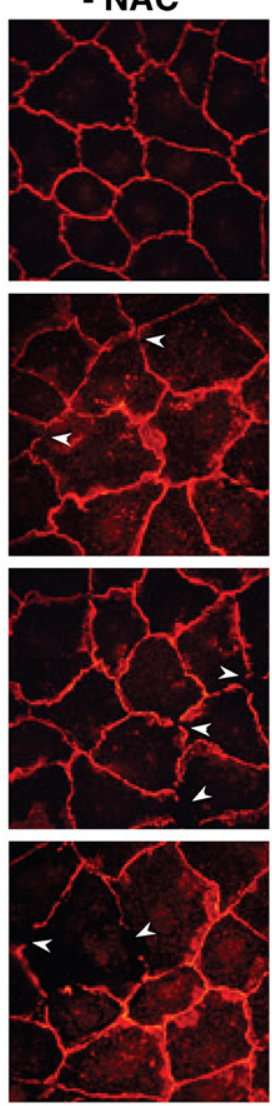

C + NAC
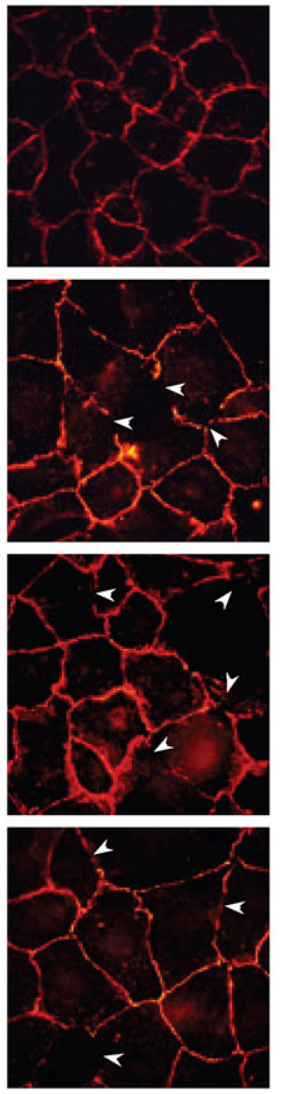

- NAC
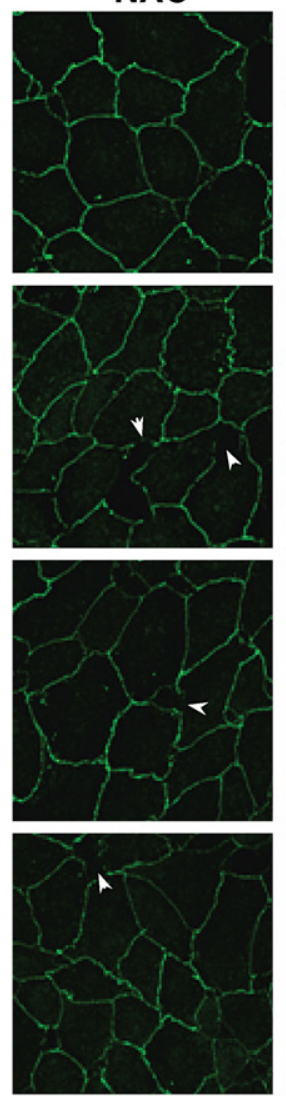

+ NAC
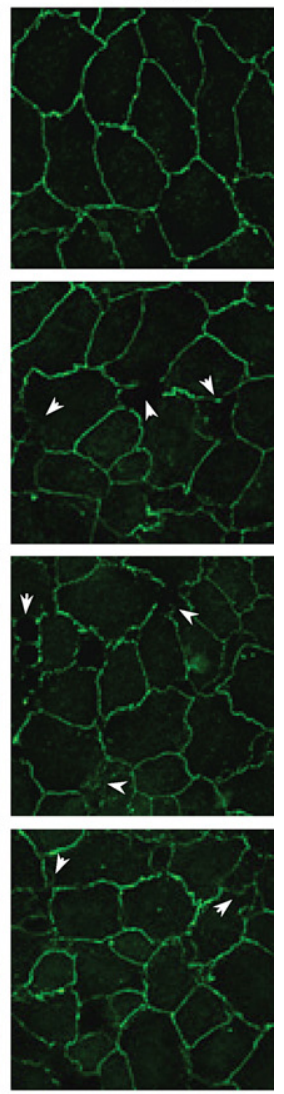

Fig. 7 - Effect of NAC on FAC disassembly, FAK phosphorylation, AJ disruption and NRK-52E cell detachment. (A) Effects of NAC $10 \mathrm{mM}$ treatment during hypoxia on paxillin (green) distribution and co-localization with actin stress fibbers (red), analyzed by immunofluorescence, phalloidin-Alexa 568 staining and confocal microscopy. NAC abrogates significantly paxillin-actin mislocation during hypoxia and early times of reoxygenation. Effects of NAC 10 mM treatment during hypoxia on E-cadherin (B) and ZO-1 (C) distribution along the membrane, visualized by immunostaining and confocal microscopy. NAC did not prevent E-cadherin nor ZO-1 transient disruption observed during hypoxia and very early times of reoxygenation (15 min-1 h), indicated by arrowheads. Scale bars: $20 \mu \mathrm{m}$. (D) NAC did not abrogate cell detachment evidenced at $12 \mathrm{~h}$ of reoxygenation, as estimated by flow cytometry. Cell detachment is expressed as mean percentage \pm SEM of detached cells vs. total cells, previously labeled with BCECF-AM. No statistically significant differences were found between R-12 h and R-12 h+NAC. 
NAC treatment reverts almost completely the transient FAK dephosphorylation and removal from FAC observed very early in the reoxygenation (data not shown).

Nevertheless, the presence of NAC during hypoxia did not have any beneficial effect on AJ or TJ disruption. In fact, NAC did not avoid E-cadherin redistribution observed during reoxygenation (15 min-3 h) or ZO-1 removal from the plasma membrane (R-30 min-R-1 h), as shown on Fig. 7B and 7C (indicated by arrowheads).

Then, we analyzed the effect of NAC administration during hypoxia in the NRK-52E cell detachment induced by $H / R$,
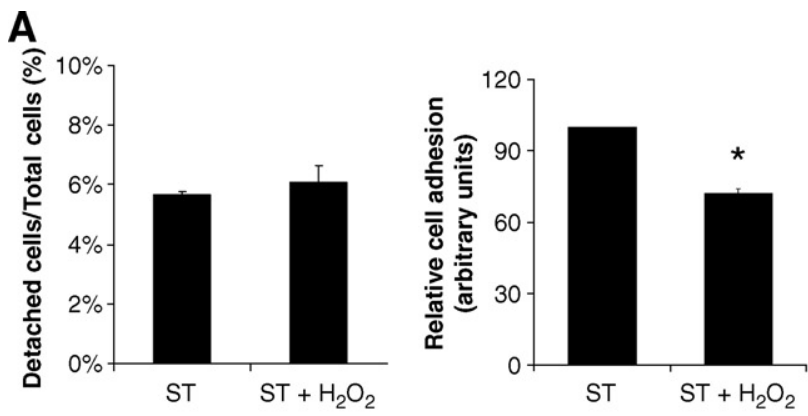

B
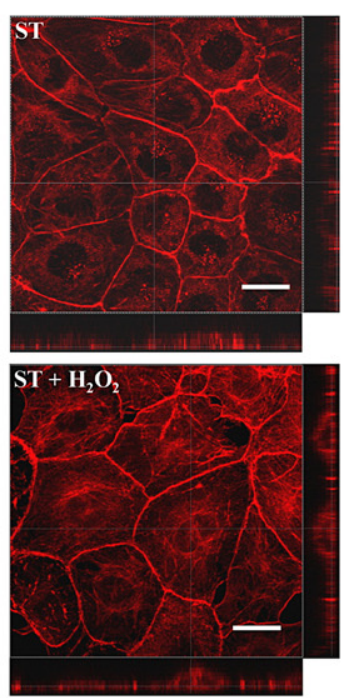

D
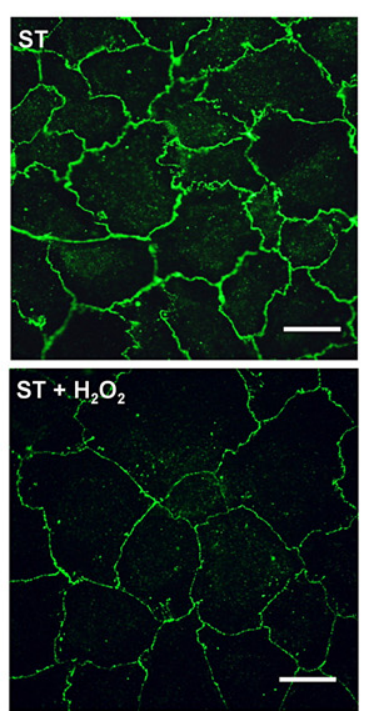

quantifying detached cells by flow cytometry. As it can be observed in Fig. 7D, the presence of NAC during hypoxia did not reduce the $\mathrm{H} / \mathrm{R}$-induced cell detachment, estimated at $12 \mathrm{~h}$ of reoxygenation.

Taken together, these results demonstrate that oxidative stress is responsible for the FAC disassembly but not the AJ and TJ disruption induced by H/R in NRK-52E cells. Moreover, they suggest that ROS-dependent FAC disassembly is not sufficient for cell detachment, which also requires ROSindependent intercellular adhesion disruption.

To study further this issue, we exposed NRK-52E cells to $1 \mathrm{mM} \mathrm{H}_{2} \mathrm{O}_{2}$ for $30 \mathrm{~min}$ to reproduce the pro-oxidant conditions generated during hypoxia. As it can be observed in Fig. 6, $1 \mathrm{mM}$ $\mathrm{H}_{2} \mathrm{O}_{2}$ induced ROS generation estimated by both $\mathrm{H}_{2}$-DCFDA and DHR, analogously to hypoxia. Confluent NRK-52E cells starved of serum for $24 \mathrm{~h}$ (ST) were used as a control for $\mathrm{H}_{2} \mathrm{O}_{2}$ treatment. As shown in Fig. $8 \mathrm{~A}, \mathrm{H}_{2} \mathrm{O}_{2}$ by itself did not induce NRK-52E cell detachment but reduced the capacity of these cells to adhere to collagen IV by $28 \%$, without affecting cell viability. This effect on cell adhesion was similar to the one described for hypoxia (Fig. 1).

$\mathrm{H}_{2} \mathrm{O}_{2}$ induced cortical and cytosolic actin reorganization in comparison with ST cells but did not provoke cell body contraction, cellular protrusion or loss of epithelial monolayer integrity (Fig. 8B). In fact, the quantification of the epithelial barrier permeability by trypan blue assay, did not show significant differences between $\mathrm{H}_{2} \mathrm{O}_{2}$-treated and ST cells (in relative units to $\mathrm{ST}=1: \mathrm{H}_{2} \mathrm{O}_{2}=1.04 \pm 0.03$ )

We next explored the effect of oxidative stress on the proteins involved in cell-cell adhesion. As it is shown in Fig. $8 \mathrm{C}$, the $\mathrm{AJ}$ were not affected by $\mathrm{H}_{2} \mathrm{O}_{2}$ treatment. The localization of E-cadherin at the membrane was not altered

Fig. 8 - Effects of $\mathrm{H}_{2} \mathrm{O}_{2}$ in NRK-52E cell adhesion. (A) Left panel: effect of $1 \mathrm{mM} \mathrm{H}_{2} \mathrm{O}_{2} 30 \mathrm{~min}$ treatment in cell detachment estimated by flow cytometry (ST = serum starved cells). Cells were previously labeled with BCECF-AM. Data are represented as mean \pm SEM from four independent experiments. $\mathrm{H}_{2} \mathrm{O}_{2}$ treatment did not induce NRK-52E cell detachment. Right panel: cell adhesion to collagen IV in $\mathrm{H}_{2} \mathrm{O}_{2}$ treated and ST cells, measured by fluorimetry, labeling the cells previously with BCECF-AM. Data are represented as mean \pm SEM from four independent experiments. ${ }^{*} P<0.01$ comparing with ST. $\mathrm{H}_{2} \mathrm{O}_{2}$ treatment reduced cell adhesion to collagen IV matrix (20\%). (B) $\mathrm{H}_{2} \mathrm{O}_{2}$ effect in actin cytoskeleton organization, cell size and monolayer integrity, determined by phalloidin-Alexa568 (red) staining. Cross-sections of the series are shown. $\mathrm{H}_{2} \mathrm{O}_{2}$ did not provoke cell contraction, cell protrusion or loss of monolayer integrity, even though it induced actin reorganization. $\mathrm{H}_{2} \mathrm{O}_{2}$ did not alter $\mathrm{AJ}(\mathrm{C})$ and $\mathrm{TJ}$ (D) integrity, by analysis of E-cadherin (red) and ZO-1 (green) distribution, respectively, visualized by immunofluorescence and confocal microscopy. (E) $\mathrm{H}_{2} \mathrm{O}_{2}$ treatment induces transient FAC disassembly, determined by immunofluorescence of paxillin (green) and phalloidin-Alexa568 staining (red). Removal of paxillin from FAC and co-localization with cortical actin is evidenced by arrowheads. All scale bars: $20 \mu \mathrm{m}$. Representative confocal images of all the experiments are shown. 
by this treatment in comparison to ST cells. Similarly, $\mathrm{H}_{2} \mathrm{O}_{2}$ treatment did not have any effect on ZO-1 distribution (Fig. 8D). These findings are in agreement with the lack of effect of $\mathrm{H}_{2} \mathrm{O}_{2}$ treatment on epithelial monolayer barrier integrity described above.

Next, we evaluated the effect of $\mathrm{H}_{2} \mathrm{O}_{2}$ on the assembly of FAC (Fig. 8E). Similarly to hypoxia, but more markedly, $\mathrm{H}_{2} \mathrm{O}_{2}$ treatment reduced stress fibers formation and provoked the loss of co-localization with paxillin at the adhesion complexes, in comparison with ST cells. $\mathrm{H}_{2} \mathrm{O}_{2}$ treatment resulted in a very peculiar paxillin distribution, characterized by a clear co-localization with cortical actin (indicated by arrowheads in Fig. 8E).

Therefore, $\mathrm{H}_{2} \mathrm{O}_{2}$ treatment produced a disruption of FAC without affecting $\mathrm{AJ}$ or $\mathrm{TJ}$ and without inducing cell detachment. Nevertheless, $\mathrm{H}_{2} \mathrm{O}_{2}$ affected the capacity of NRK-52E cells to attach to collagen IV matrix. This may confirm that the disruption of FAC is not sufficient to induce cell detachment unless it is accompanied by alterations in the intercellular adhesion (AJ and TJ).

In summary, ROS generated during hypoxia are responsible for focal adhesion and actin cytoskeleton alterations in NRK52E cells submitted to $H / R$, contributing to cell detachment. However, ROS did not affect intercellular adhesion, which is required for cell shedding after ischemia.

\section{Discussion}

The present work describes the sequence of molecular and cellular processes mediating proximal epithelial cell detachment consequently to sublethal renal ischemia-in vitro mimicking conditions, elucidating also, for the first time, the contribution of the oxidative stress on this effect. By means of an experimental in vitro model, we have demonstrated that ROS generated during deprivation phase, from oxygen and nutrients, mediates alterations in cell-matrix adhesion but not in cell-cell adhesion.

Using NRK-52E cells, we have established an in vitro model, which includes oxygen and nutrient alterations and reproduces the proximal epithelial cell detachment observed in the renal I/R rat model. No significant cell death was found in our $\mathrm{H} / \mathrm{R}$ model, consistent with the occurrence of a moderate decrease in ATP levels. ATP depleting compounds have been extensively used in an attempt to mimic ischemic injury provoking a very pronounced ATP reduction and leading to cell death [3]. In fact, we have observed that Antimycin A treatment provoked a drastic reduction of the intracellular ATP levels and consequently apoptosis and necrosis in NRK52E cells [54]. On the other hand, it has been reported that hypoxia $\left(1 \% \mathrm{O}_{2}, 36 \mathrm{~h}\right)$ by itself induced non-lethal renal epithelial dysfunction in the proximal human epithelial cell line HK-2 [21].

Similarly to the observations made using the in vivo I/R rat model [10], proximal epithelial cell detachment is evident during recovery/reoxygenation phase under our in vitro conditions. Nevertheless, the results presented here proved that this phenomenon is a consequence of mechanisms triggered both during hypoxia and reoxygenation phases. In addition, the complete recuperation of H/R-induced morpho- logical changes in NRK-52E cells after $12 \mathrm{~h}$ of recovery is analogous to the proximal epithelium restoration described in vivo after 24-48 h of reperfusion [2].

Our results demonstrate that nutrients and oxygen alterations affect actin cytoskeleton organization (cortical actin and stress fibers), leading to NRK-52E cell contraction, protrusion and detachment. Actin alterations have been extensively described in the proximal tubule injury, using renal I/R animal models [4] and in vitro ATP depletion systems [22]. Mechanisms underlying actin alterations, as a direct effect of changes in ATP levels and oxygen tension, have not been completely elucidated. However, I/R or ATP depletion/repletion affects the activity of actin binding proteins (ABP) which may modulate actin polimerization in an ATP-dependent manner [23]. Regulation of $\mathrm{ABP}$ activity in response to the ATP alterations observed in our H/R system, could contribute to the actin cytoskeleton reorganization described here. The Rho family regulates most of the actin-dependent processes in the cell. Rac1 signaling induces actin polymerization at the cell periphery; RhoA induces stress fiber and FAC assembly [5]. RhoA and Rac1 also regulate $\mathrm{TJ}$ and $\mathrm{AJ}$ assembly and function in epithelial cells [24,25]. Here we have found significant changes in Rac1 and RhoA activity during H/R in NRK-52E cells. The low RhoA activity during hypoxia could be mediated by ATP depletion and could contribute to ischemic cytoskeletal injury, as it has been previously suggested [6]. The two subsequent periods of higher RhoA activity could be related to the induction of cell body contraction and to in the later recovery of focal adhesions and intercellular unions, respectively. In fact, the use of C3 exoenzyme, a specific inhibitor of RhoA activity, in our $\mathrm{H} / \mathrm{R}$ protocol supports this hypothesis, since very early cell contraction and protrusion were delayed in its presence, which could be also affecting subsequent FAC and AJ recovery. Regarding this, McBeath et al. [26] demonstrated that cell shape modulates RhoA activity, which regulates, in turn, contractility and drives focal adhesion assembly [27]. However, even if changes in RhoA activity mediate cell alterations during $H / R$, these changes appear not to be essential for cell detachment, as the use of $\mathrm{C} 3$ revealed (Fig. 3E). Strikingly, we have observed a significant activation of Rac1 during hypoxia, an effect which has not been previously detected using other $H / R$ or $I / R$ experimental models [8,28]. Moreover, Rac1 activation is involved in NRK52E cell contraction, protrusion and detachment during $H / R$ since the use of the specific Rac1 inhibitor NSC23766 reduced all these phenomena significantly (Fig. 3B and C). These results agree with those recently published demonstrating that Rac1 activity is critical for actin stress fiber formation and focal adhesion complex assembly in MEFs, acting downstream or in parallel to RhoA activity [53]. Furthermore, coordinated action of Rac1 and RhoA activities appears to be important for events involving actin cytoskeleton reorganization and consequently, a crosstalk between Rac1 and RhoA in the NRK-52E cell response to $H / R$ is conceivable, as other authors have described using other cell types [28].

Our findings also demonstrate that the continuous distribution of E-cadherin and $\beta$-catenin along the membrane was transiently disrupted in NRK-52E cells submitted to $H / R$, without detectable changes in total E-cadherin or $\beta$-catenin levels. This phenomenon was contemporary with the loss of 
epithelial monolayer integrity as well as with cell body protrusion and detachment. It has been reported that ATP depletion may induce AJ disruption leading to E-cadherin internalization towards the cytosol [29]. Consistent with this, our results suggest that intact E-cadherin/catenin complexes moved from the membrane to the cytosol and relocated later on, as it has been also previously proposed for ATP depletion systems [30] and for short-term renal ischemia [31]. Absence of AJ components degradation would facilitate the rapid intercellular union restoration and monolayer integrity recovery observed here. However, during more severe ischemia or more pronounced ATP depletion in MCDK and in NRK-52E cells E-cadherin can also suffer selective degradation [13,32].

It is important to note that E-cadherin also controls TJ assembly structures [33] in systems which include ATP alterations [14]. In fact, our results demonstrate that the continuous distribution of $\mathrm{ZO}-1$ along the membrane is also interrupted during $\mathrm{H} / \mathrm{R}$. Changes in $\mathrm{ZO}-1$ distribution following $E$-cadherin/ $\beta$-catenin complexes disruption correlated with transient epithelial integrity barrier alterations reported here. It has been described that ATP depletion leads ZO-1 to form insoluble complexes and associate with the cytoskeleton [16]. ZO-1 integrating those complexes could compromise the correct structure and functionality of the TJ in our H/R model and would also facilitate NRK-52E cell detachment. Following AJ and ATP levels recovery, TJ reassembly might involve both RhoA activation and Rac1 inactivation, among other factors, as previously suggested [34]. Moreover, Bruewer et al. [35] recently demonstrated that activation or inactivation of a single GTPase enhanced intercellular permeability, proposing that epithelial cell-cell union alterations involve an imbalance in active vs. resting GTPases levels, as the results presented here have indicated.

We also demonstrated here that $H / R$ induces transient disruption of FAC in NRK-52E cells by disassembly of their components, coincident with cell protrusion and detachment. We observed reversible redistribution of paxillin and p-FAK as well as FAK dephosphorylation during $H / R$. This redistribution may be involved in the FAC disassembly and the cell detachment observed in our $\mathrm{H} / \mathrm{R}$ conditions. In addition, dephosphorylation of FAK can contribute to the loss of interaction between FAK and paxillin and loss of FAK location in the focal contacts [36]. Changes in the phosphorylation of the FAC components have been associated with ATP alterations in isolated rabbit proximal tubules [11] as well as in endothelial cells submitted hypoxia [37]. Regarding this, unpublished data from our laboratory indicate a reversible decrease in proteins tyrosine phosphorylation concomitant with diminished ATP levels, as observed elsewhere. More recently, dephosphorylation of FAK has been reported in the presence of HIF$1 \alpha$ upregulation related with adhesion and migration, in smooth muscle cells [38]. Preliminary results of our laboratory indicated that the same H/R protocol used here induces HIF- $1 \alpha$ protein accumulation during hypoxia in the proximal human epithelial cell line HK-2 [55]. On the other hand, although alterations in paxillin and FAK localization have been proposed to be the result of protein degradation [39], we have not observed changes in the total levels of either protein. Indeed, we postulate here that redistribution but not degradation of FAC components during FAC disassembly facilitates the rapid recovery of the system after ATP and oxygen repletion.

It is widely accepted that oxidative stress, in particular the ROS generated during the reperfusion period, underlies renal tissue damage associated to I/R. This assumption is also based in the protective effects of antioxidants administration in experimental models of I/R [1]. Here we have demonstrated that NRK-52E cells showed an increased generation of ROS during hypoxia, which was rapidly balanced during reoxygenation, possibly due to transient induction of MnSOD activity, among other factors. MnSOD is a relevant antioxidant enzyme implicated in the oxidative stress cell management. Several reports indicate that MnSOD protects the tissues from I/R damage, including renal tissue in vivo [40].

ROS generation during hypoxia was also reported in several cell types including alveolar pulmonary epithelial A549 cells [41], HEK293 and Hep.B cells [42] and in opossum kidney (OK) cells [43]. Otherwise, several reports describe ROS generation during the reoxygenation period [44]. ROS generated during hypoxia could arise from several sources. It has been suggested that hypoxia partially inhibits the mitochondrial electron transport resulting in generation of ROS and ATP depletion. Additionally, NADPH oxidase has been proposed to play an active role in the maintenance of intracellular ROS balance [45]. Rac1 is considered as a cytosolic subunit of the NADPH oxidase complex that could be involved in the ROS generation during $\mathrm{H} / \mathrm{R}$ systems [46]. In fact, we have reported here Rac1 activation during hypoxia in NRK-52E cells, even though the use of NAC during hypoxia indicated that Rac1 activation is downstream ROS generation in our H/R in vitro model (Fig. 6).

Based on the results obtained using antioxidants, we postulate that ROS generated during hypoxia are responsible for FAC disassembly and actin cytoskeleton reorganization, which lead to cell contraction and protrusion. $\mathrm{H}_{2} \mathrm{O}_{2}$ treatment confirms the ROS involvement in FAC disassembly and partially reproduces the hypoxia effects on actin cytoskeleton reorganization. As it mentioned above, Rac1 activity is regulated by $\mathrm{ROS}$ in our $\mathrm{H} / \mathrm{R}$ model and also $\mathrm{H}_{2} \mathrm{O}_{2}$ treatment induced Rac1 activation (data not shown). In this context, it has been reported recently that ROS mediated the remodeling of actin cytoskeleton and AJ, in pulmonary artery endothelial cells submitted to H/R, involving RhoGTPases activities [28].

The use of antioxidants in our system prevents paxillin and p-FAK delocalization induced by hypoxia, confirming that ROS are involved in FAC disassembly. Moreover, NAC abrogates the transient FAK dephosphorylation induced by $\mathrm{H} / \mathrm{R}$, which may contribute to FAC assembly maintenance. However, it has been reported that $\mathrm{H}_{2} \mathrm{O}_{2}$ treatment induced tyrosine phosphorylation of FAC proteins such as paxillin or FAK, in endothelial cells [47]. It is know that ROS mediates cell adhesion under physiological stimuli [48], but the role of ROS in FAC regulation under pathological situations remains controversial.

Otherwise, the use of NAC during hypoxia did not reduce the NRK-52E cell detachment observed late in the reoxygenation (12-24 h). This result could be explained based on two facts: the observations made by Gallant et al. [49] demonstrating that FAC assembly provides only the $30 \%$ of total cell adhesive forces and our own observations of the lack of NAC 
beneficial effect on $\mathrm{AJ}$ and $\mathrm{TJ}$ disruption induced by $\mathrm{H} / \mathrm{R}$. Moreover, $\mathrm{H}_{2} \mathrm{O}_{2}$ treatment did not affect $\mathrm{AJ}$ or TJ integrity, confirming that, in our H/R model, ROS are not involved in cell-cell adhesion alterations and more importantly, that cell detachment under $\mathrm{H} / \mathrm{R}$ requires intercellular adhesion disturbance, which plays more crucial role than FAC disassembly. Indeed, Neumann and Affolter [50], recently reviewed how epithelial tissues rearrangements might be controlled by modulating the adhesion dynamics of the AJs.

In summary, we have reported here the events leading to proximal tubular epithelial cell detachment as a response to sublethal ischemia, using an experimental $\mathrm{H} / \mathrm{R}$ in vitro model. By means of this model, we have explored endogenous mechanisms underlying renal epithelium impairment subsequent to moderate ATP and oxygen alterations. We have clearly determined the involvement of the oxidative stress in cell-matrix adhesion but not in cell-cell adhesion, in the epithelial cell response to ischemia. In spite of the efforts made to improve renal I/R-injury outcome, this situation still exhibits a high organ failure rate. The findings reported here may shed light on this problem and contribute to the design of new and more effective therapeutic strategies, based on in vitro experimental approaches.

\section{Acknowledgments}

This work was supported by grants from Fondo de Investigación Sanitaria, FIS (PI01/3001), FIS (PI03/0681) and CAM (08.3/ 0001.1/2003) to L.G.B; Fundación Biomédica MMA (2004/010) to F.M./L.G.B; MEC (SAF2003-03713) to D.P.-S. D.S-M is funded by MEC (FPU fellowship), MME by MMA (2004/010), KS by CSIC (I3P fellowship) and LA by ISCIII/IRSIN L.G.B. is supported by Contrato Investigador FIS 01/3001 from Instituto de Salud Carlos III.

We are very grateful to Diego Megías and Dolores Morales for confocal technical assistance, to D. Amrán Cohen for helping with the in vitro system set up and to Dr. T. Iglesias for useful comments.

F.M. in memoriam.

\section{REFERENCES}

[1] R.W. Schrier, W. Wang, B. Poole, A. Mitra, Acute renal failure: definitions, diagnosis, pathogenesis, and therapy, J. Clin. Invest. 114 (2004) 5-14.

[2] T.A. Sutton, B.A. Molitoris, Mechanisms of cellular injury in ischemic acute renal failure, Semin. Nephrol. 18 (5) (1998) 490-497.

[3] P.C. Dagher, Modeling ischemia in vitro: selective depletion of adenine and guanine nucleotide pools, Am. J. Physiol.: Cell Physiol. 279 (2000) C1270.

[4] B.A. Molitoris, Actin cytoskeleton in ischemic acute renal failure, Kidney Int. 66 (2004) 871-883.

[5] S. Etienne-Manneville, A. Hall, Rho GTPases in cell biology, Nature 420 (2002) 629-635.

[6] N. Raman, S.J. Atkinson, Rho controls actin cytoskeletal assembly in renal epithelial cells during ATP depletion and recovery, Am. J. Physiol.: Cell Physiol. 276 (1999) C1312-C1324.
[7] M.A. Hallett, P.C. Dagher, S.J. Atkinson, Rho GTPases show differential sensitivity to nucleotide triphosphate depletion in a model of ischemic cell injury, Am. J. Physiol.: Cell Physiol. 285 (2003) C129-C138.

[8] A. Caron, R. Desrosiers, R. Beliveau, Kidney ischemia-reperfusion regulates expression and distribution of tubulin subunits, beta-actin and rho GTPases in proximal tubules, Arch. Biochem. Biophys. 134 (2004) 31-46.

[9] B. Geiger, A. Bershadsky, R. Pankov, K.M. Yamada, Transmembrane crosstalk between the extracellular matrix-cytoskeleton crosstalk, Nat. Rev., Mol. Cell Biol. 2 (2001) 793-805.

[10] A. Molina, M. Ubeda, M.M. Escribese, L. Garcia-Bermejo, D. Sancho, G.P. de Lema, F. Liano, C. Cabanas, F.

Sanchez-Madrid, F. Mampaso, Renal ischemia/reperfusion injury: functional tissue preservation by anti-activated \{beta\} 1 integrin therapy, J. Am. Soc. Nephrol. 16 (2005) 374-382.

[11] J.M. Weinberg, M.A. Venkatachalam, N.F. Roeser, R.A. Senter, I. Nissim, Energetic determinants of tyrosine phosphorylation of focal adhesion proteins during hypoxia/ reoxygenation of kidney proximal tubules, Am. J. Pathol. 158 (2001) 2153-2164.

[12] C.J. Gottardi, C.M. Niessen, B.M. Gumbiner, The adherens junction, in: B.D. Hames, D.M. Glover, M. Beckerle (Eds.), Cell Adhesion, The Frontier in Molecular Biology Series, Oxford Univ. Press, 2002, Chap. 8.

[13] K.T. Bush, T. Tsukamoto, S.K. Nigam, Selective degradation of E-cadherin and dissolution of E-cadherin-catenin complexes in epithelial ischemia, Am. J. Physiol.: Renal Physiol. 278 (2000) F847-F852.

[14] B.M. Denker, S.K. Nigam, Molecular structure and assembly of the tight junction, Am. J. Physiol.: Renal Physiol. 274 (1998) F1-F9.

[15] A.K. Rajasekaran, S.A. Rajasekaran, Role of Na-K ATPase in the assembly of tight junctions, Am. J. Physiol.: Renal Physiol. 285 (2003) F388-F396.

[16] T. Tsukamoto, S.J. Nigam, Tight junctions proteins form large complexes associate with the cytoskeleton in an ATP depletion model for reversible junction assembly, J. Biol. Chem. 272 (1997) 16133-16139.

[17] K. Doi, Y. Suzuki, A. Nakao, T. Fujita, E. Noiri, Radical scavenger edaravone developed for clinical use ameliorates ischemia/reperfusion injury in rat kidney, Kidney Int. 65 (2004) 1714-1723.

[18] S. Van Wetering, J.D. van Buul, S. Quik, F.P.J. Mul, E.C. Anthony, J.-P.t. Klooster, J.G. Collard, P.L. Hordijk, Reactive oxygen species mediate Rac-induced loss of cell-cell adhesion in primary human endothelial cells, J. Cell Sci. 115 (2002) 1837-1846.

[19] R.K. Rao, S. Basuroy, V.U. Rao, K.J. Karnaki Jr., A. Gupta, Tyrosine phosphorylation and dissociation of occludin-ZO-1 and E-cadherin-b-catenin complexes from the cytoskeleton by oxidative stress, Biochem. J. 368 (Pt2) (2002) 471-481.

[20] J.L. Oliva, D. Perez-Sala, A. Castrillo, N. Martinez, F.J. Canada, L. Bosca, J.M. Rojas, The cyclopentenone 15-deoxy-delta 12,14-prostaglandin J2 binds to and activates H-Ras, Proc. Natl. Acad. Sci. U. S. A. 100 (8) (2003) 4772-4777.

[21] M.O. Leonard, D.C. Cottell, C. Godson, H.R. Brady, C.T. Taylor, The role of HIF-1 alpha in transcriptional regulation of the proximal tubular epithelial cell response to hypoxia, J. Biol. Chem. 278 (41) (2003) 40296-40304.

[22] R. Bacallao, A. Garfinkel, S. Monke, G. Zampighi, L.J. Mandel, ATP depletion: a novel method to study junctional properties in epithelial tissues: I. Rearrangement of the actin cytoskeleton, J. Cell Sci. 107 (1994) 3301-3313.

[23] S.J. Atkinson, M.A. Hosford, B.A. Molitoris, Mechanism of actin polymerization in cellular ATP depletion, J. Biol. Chem. 279 (2004) 5194-5199. 
[24] A. Nusrat, M. Giry, J.R. Turner, S.P. Colgan, C.A. Parkos, D. Carnes, E. Lemichez, P. Boquet, J.L. Madara, Rho protein regulates tight junctions and perijunctional actin organization in polarized epithelia, Proc. Natl. Acad. Sci. U. S. A. 92 (1995) 10629-10633.

[25] T.-S. Jou, E.E. Schneeberger, W. James Nelson, Structural and functional regulation of tight junctions by RhoA and Rac1 small GTPases, J. Cell Biol. 142 (1998) 101-115.

[26] R. McBeath, D.M. Pirone, C.M. Nelson, K. Bhadriraju, C.S. Chen, Cell shape, cytoskeletal tension, and RhoA regulate stem cell lineage commitment, Dev. Cell 6 (4) (2004) 483-495.

[27] M. Chrzanowska-Wodnicka, K. Burridge, Rho-stimulated contractility drives the formation of stress fibers and focal adhesions, J. Cell Biol. 133 (6) (1996) 1403-1415.

[28] B. Wojciak-Stothard, L.Y.F. Tsang, S.G. Haworth, Rac and Rho play opposing roles in the regulation of hypoxia/ reoxygenation-induced permeability changes in pulmonary artery endothelial cells, Am. J. Physiol.: Lung Cell. Mol. Physiol. 288 (2005) L749-L760.

[29] L.J. Mandel, R.B. Doctor, R. Bacallao, ATP depletion: a novel method to study junctional properties in epithelial tissues. II. Internalization of $\mathrm{Na}+, \mathrm{K}(+)$-ATPase and E-cadherin, J. Cell Sci. 107 (1994) 3315-3324.

[30] V.R. Price, C.A. Reed, W. Lieberthal, J.H. Schwartz, ATP depletion of tubular cells causes dissociation of the zonula adherens and nuclear translocation of \{beta\}-catenin and LEF-1, J. Am. Soc. Nephrol. 13 (2002) 1152-1161.

[31] K.T. Bush, S.H. Keller, S.K. Nigam, Genesis and reversal of the ischemic phenotype in epithelial cells, J. Clin. Invest. 106 (5) (2000) 621-626.

[32] M.D. Covington, K.J. Bayless, R.C. Burghardt, G.E. Davis, A.R. Parrish, Ischemia-induced cleavage of cadherins in NRK cells: evidence for a role of metalloproteinases, Am. J. Physiol.: Renal Physiol. 290 (1) (2006) F-43-F-51.

[33] J.A. Tunggal, I. Helfrich, A. Schmitz, H. Schwarz, D. Gunzel, M. Fromm, R. Kemler, T. Krieg, C. Niessen, E-cadherin is essential for in vivo epidermal barrier function by regulating tight junctions, EMBO J. 24 (2005) 1146-1156.

[34] S. Gopalakrishnan, K.W. Dunn, J.A. Marrs, Rac1, but not RhoA, signaling protects epithelial adherens junction assembly during ATP depletion, Am. J. Physiol.: Cell Physiol. 283 (2002) C261-C272.

[35] M. Bruewer, A.M. Hopkins, M.E. Hobert, A. Nusrat, J.L. Madara, RhoA, Rac1 and Cdc42 exerts distinct effects on epithelial barrier via selective structural and biochemical modulation of junctional proteins and F-actin, Am. J. Physiol.: Cell Physiol. 287 (2004) C-327-C-335.

[36] J.T. Parsons, Focal adhesion kinase: the first ten years, J. Cell Sci. 116 (2003) 1409-1416.

[37] Y Seko, T.N., H. Sabe, K. Tobe, T. Kadowaki, R. Nagai, Hypoxia induces activation and subcellular translocation of focal adhesion kinase (p125(FAK)) in cultured rat cardiac myocytes, Biochem. Biophys. Res. Commun. 262 (1999) 290-296.

[38] K.M. Corley, C.J. Taylor, B. Lilly, Hypoxia inducible factor 1alpha modulates adhesion, migration and FAK phosphorylation in vascular smooth muscle cells, J. Cell. Biochem. 96 (5) (2005) 971-985.

[39] H. Mao, Y. Wang, Z. Li, K.L. Ruchalski, X. Yu, J.H. Schwartz, S.C. Borkan, Hsp72 Interacts with paxillin and facilitates the reassembly of focal adhesions during recovery from ATP depletion, J. Biol. Chem. 279 (2004) 15472-15480.

[40] D.L. Cruthirds, L. Novak, KM. Akhi, P.W. Sanders, J.A. Thompson, L.A. MacMillan-Crow, Mitochondrial targets of oxidative stress during renal ischemia/reperfusion, Arch. Biochem. Biophys. 412 (2003) 27-33.

[41] L.A. Dada, N.S. Chandel, K.M. Ridge, C. Pedemonte, A.M. Bertorello, J.I. Sznajder, Hypoxia-induced endocytosis of $\mathrm{Na}$, $\mathrm{K}$-ATPase in alveolar epithelial cells is mediated by mitochondrial reactive oxygen species and PKC-\{zeta\}, J. Clin. Invest. 111 (2003) 1057-1064.

[42] K.D. Mansfield, M.C. Simon, B. Keith, Hypoxic reduction in cellular glutathione levels requires mitochondrial reactive oxygen species, J. Appl. Physiol. 97 (4) (2004) 1358-1366.

[43] Y.K. Kim, S.K. Lee, M.S. Ha, J.S. Woo, J.S. Jung, Differential role of reactive oxygen species in chemical hypoxia-induced cell injury in opossum kidney cells and rabbit renal cortical slices, Exp. Nephrol. 2002 (10) (2005) 275-284.

[44] P. Saikumar, M. Venkatachalam, Role of apoptosis in hypoxic/ ischemic damage in the kidney, Semin. Nephrol. 23 (2003) 511-521.

[45] N.S. Chandel, P.T. Schumacker, Cellular oxygen sensing by mitochondria: old questions, new insight, J. Appl. Physiol. 88 (2000) 1880-1889.

[46] K.S. Kim, K. Takeda, R. Sethi, J.B. Pracyk, K. Tanaka, Y.F. Zhou, Z.X. Yu, V.J. Ferrans, J.T. Bruder, I. Kovesdi, K. Irani, P. Goldschmidt-Clermont, T. Finkel, Protection from reoxygenation injury by inhibition of rac1, J. Clin. Invest. 101 (9) (1998) 1821-1826.

[47] S. Vepa, W.M. Scribner, N.L. Parinandi, D. English, J.G.N. Garcia, V. Natarajan, Hydrogen peroxide stimulates tyrosine phosphorylation of focal adhesion kinase in vascular endothelial cells, Am. J. Physiol.: Lung Cell. Mol. Physiol. 277 (1999) L150-L158.

[48] P. Chiarugi, G. Pani, E. Giannoni, L. Taddei, R. Colavitti, G. Raugei, M. Symons, S. Borrello, T. Galeotti, G. Ramponi, Reactive oxygen species as essential mediators of cell adhesion: the oxidative inhibition of a FAK tyrosine phosphatase is required for cell adhesion, J. Cell Biol. 161 (5) (2003) 933-944.

[49] N.D. Gallant, K.E. Michael, A.J. Garcia, Cell adhesion strengthening: contributions of adhesive area, integrin binding, and focal adhesion assembly, Mol. Biol. Cell 16 (9) (2005) 4329-4340.

[50] M. Neumann, M. Affolter, Remodelling epithelial tubes trough cell rearrangements: from cells to molecules, EMBO Rep. 7 (1) (2006) 36-40.

[51] Y. Gao, J.B. Dickerson, F. Guo, J. Zheng, Y. Zheng, Rational design and characterization of a Rac GTPase-specific small molecule inhibitor, Proc. Natl. Acad. Sci. U. S. A. 101 (20) (2004) 7618-7623.

[52] K.J.M. Marler, R. Kozma, S. Ahmed, J.M. Dong, C. Hall, L. Lim, Outgrowth of neurites from NIE-115 neuroblastoma cells is prevented on repulsive substrates trough the action of PAK, Mol. Cell. Biol. 25 (12) (2005) 5226-5241.

[53] F. Guo, M. Debidda, L. Yang, D.A. Williams, Y. Zheng, Genetic deletion of Rac1 GTPase reveals its critical role in actin stress fiber formation and focal adhesion complex assembly, J. Biol. Chem. 281 (27) (2006) 18652-18659.

[54] M.M. Escribese, D. Sáenz-Morales, M. Garcia-Martos, D. Amrán, E. Conde, L. Alegre, F. Liaño, M.L. Garcia-Bermejo, Moderate renal ischemia/reperfusion tubular damage is reproduced by an in vitro model (in preparation).

[55] L. Alegre, M. Garcia-Martos, D. Sáenz-Morales, E. Conde, M.M. Escribese, M. López-Cabrera, J.A. Sanchez-Tomero, R. Selgas, M.L. Garcia-Bermejo, HIF-1alpha is required for human proximal tubule epithelial cells survival after moderate ischemia (in preparation). 